\title{
Characterization of PM, PAHs and Gaseous Pollutants Emitted from Sintering Process and Electric Arc Furnace
}

\section{Tang Wei Chen ${ }^{1}$, Jyh Cherng Chen², Zhen Shu Liư ${ }^{3}$, Kai Hsien Chi', Moo Been Chang ${ }^{{ }^{*}}$}

${ }^{1}$ Graduate Institute of Environmental Engineering, National Central University, Taoyuan, Taiwan

${ }^{2}$ Department of Environmental Engineering and Science, Feng Chia University, Taichung, Taiwan

${ }^{3}$ Department of Safety Health and Environmental Engineering, Ming Chi University of Technology, New Taipei, Taiwan

${ }^{4}$ Institute of Environmental and Occupational Health Sciences, National Yang Ming Chiao Tung University, Taipei, Taiwan

\section{ABSTRACT}

Iron and steel industry is crucial for economic development. However, large exhaust volume and complex feeding of the steel-making process results in enormous emissions of air pollutants such as particulate matter $(\mathrm{PM})$, sulfur oxides $\left(\mathrm{SO}_{\mathrm{x}}\right)$, nitrogen oxides $\left(\mathrm{NO}_{\mathrm{x}}\right)$, polycyclic aromatic hydrocarbon (PAHs) and carbon monoxide (CO). This study sampled and analyzed the concentrations of PM, PAHs, $\mathrm{SO}_{x}, \mathrm{NO}_{\mathrm{x}}$ and $\mathrm{CO}$ at the inlet and outlet of the air pollution control devices (APCDs) adopted in sintering process (SP) and electric arc furnaces (EAF), respectively, to evaluate the performance of APCDs and emission characteristics of these air pollutants. The results show that filterable PM (FPM) concentrations measured at stacks of SP and EAF are $8.2 \pm 1.3$ and $13.6 \pm$ $2.2 \mathrm{mg} \mathrm{Nm}^{-3}$, respectively. The FPM 2.5 concentrations emitted from SP and EAF are $1.8 \pm 0.5$ and $3.2 \pm 1.1 \mathrm{mg} \mathrm{Nm}^{-3}$, respectively, while the condensable PM (CPM) concentrations emitted from $\mathrm{SP}$ and EAF are measured as $37.7 \pm 1.3$ and $3.4 \pm 0.8 \mathrm{mg} \mathrm{Nm}^{-3}$, respectively. Moreover, the flue gas desulfurization (FGD) and selective catalytic reduction (SCR) equipped in SP removed $82 \%$ and $58 \%$ of $\mathrm{SO}_{\mathrm{x}}$ and $\mathrm{NO}_{\mathrm{x}}$, respectively, whereas $\mathrm{SO}_{\mathrm{x}}$ and $\mathrm{NO}_{\mathrm{x}}$ emitted from $\mathrm{EAF}$ are relatively low ( $<1 \mathrm{ppm}$ ). The overall PAH removal efficiencies achieved with the APCDs adopted by SP and EAF are $72 \%$ and $26 \%$, respectively. For total toxicity equivalency quantity (TEQ) PAH concentrations, similar results for SP $\left(5.45 \mu \mathrm{g}-\mathrm{BaP}_{\mathrm{eq}} \mathrm{Nm}^{-3}\right)$ and $\mathrm{EAF}\left(4.74 \mu \mathrm{g}-\mathrm{BaP}_{\mathrm{eq}} \mathrm{Nm}^{-3}\right)$ are obtained. Moreover, the diagnosis ratios of FL/CHR, FL/(BaA + $\mathrm{CHR}), \mathrm{Pyr} / 5-\mathrm{MC}$ and $\mathrm{Pyr} /(\mathrm{BaA}+\mathrm{CHR})$ are suggested as the indicators for EAF. The emission factors calculated indicate that operating conditions of the APCDs in the SP investigated are well controlled. The concentrations of air pollutants emitted from SP investigated are lower than other studies. On the other hand, the concentrations of FPM and $\mathrm{PM}_{2.5}$ emitted from EAF are higher than other studies. However, $\mathrm{NO}_{\mathrm{x}}, \mathrm{SO}_{\mathrm{x}}$ and $\mathrm{PAHs}$ are well controlled. Moreover, the $\mathrm{CO}$ emission factors calculated from these two steel-making processes are higher than most reports. Overall, the operation of APCDs should be improved to reduce air pollutants emitted from these two steel-making processes.

Keywords: Iron and steel industry, Nitrogen oxides $\left(\mathrm{NO}_{\mathrm{x}}\right)$, Sulfur oxides $\left(\mathrm{SO}_{\mathrm{x}}\right)$, Particulate matter (PM), Polycyclic aromatic hydrocarbons (PAHs)

\section{INTRODUCTION}

Iron and steel industry is crucial for economic development. According to the statistics released by the World Steel Association, annual global crude steel production reached 1,869 million tonnes in 2019, and the output has been increasing since 1950 (Association 2020). Accounting 
for $50 \%$ of global production, China is the largest iron and steel producing country. The crude steel production in Taiwan (22.4 million metric tons in 2017) ranked eleventh in the world, accounting for $1.33 \%$ of global output, of which crude steel produced by SP and EAF accounted for $61 \%$ and $39 \%$, respectively. According to the statistical data released by the Taiwan EPA, PM, $\mathrm{PM}_{2.5}, \mathrm{SO}_{\mathrm{x}}$, $\mathrm{NO}_{\mathrm{x}}$ and $\mathrm{CO}$ emitted from the steel-making process accounted for $15.9 \%, 17.5 \%, 16.7 \%, 13.0 \%$, $8.31 \%$ and $82.1 \%$ of industrial emissions (TEDS 10.0, 2016) in Taiwan, respectively, confirming the importance of the steel-making process as a source of air pollutants. Previous studies also indicate that iron and steel industries are major contributors of PM and persistent organic pollutants (POPs) in the vicinity (Amodio et al., 2012; Van Thuong et al., 2014; Xiao et al., 2013).

Particulate matter (PM) including filterable and condensable PM is one of the most important pollutants emitted from steel-making processes. FPM comprises of the particles emitted directly from a source as a solid or liquid at release conditions and is captured on the filter of a stack sampling train. On the other hand, CPM consists of material in the vapor phase at stack conditions that condenses and reacts upon cooling and dilution in the ambient air to form solid on liquid PM after exiting the stack. CPM passes through the filter and can be captured by the impingers of the sampling train. $\mathrm{PM}_{2.5}$ emissions would be greatly underestimated if CPM is ignored since CPM accounts for a significant portion of total $\mathrm{PM}_{2.5}$ emissions (Yang et al., 2014; Yang et al., 2015).

Steel-making process can be classified into sintering process (SP) and electric arc furnace (EAF) process. The former primarily uses iron ore as raw material for making iron in a blast furnace and steel in a basic oxygen furnace; the latter uses scrap steel as the primary feeding material. Because the feeding of iron and steel-making process is complex and requires large volume of raw materials, air pollutants are inevitably produced. The concentration of air pollutants emitted from steel-making processes varies greatly, depending on operating conditions and APCDs adopted. In addition to PM, the iron and steel industry is also one of the primary sources of $\mathrm{SO}_{\mathrm{x}}$ and $\mathrm{NO}_{\mathrm{x}}$ emissions in China (Li et al., 2019a). Tang et al. (2020) investigated the emissions of air pollutants from iron and steel industry in China, indicating that compared with coke making process, basic oxygen and blast furnaces, the sintering process was the largest emitter among the iron and steel production processes in China, accounting for $69.52 \%$ of $\mathrm{SO}_{2}, 75.48 \%$ of $\mathrm{NO}_{\mathrm{x}}$, $45.81 \%$ of $\mathrm{PM}_{10}$, and $47.99 \%$ of $\mathrm{PM}_{2.5}$ emissions, respectively. Additionally, Yang et al. (2015) measured the concentrations of $\mathrm{PM}_{2.5}$ and water-soluble ions emitted from steel plants, indicating that sintering and EAF has high FPM 2.5 and CPM emission concentrations, while $\mathrm{SO}_{4}{ }^{2-}$ is the highest water-soluble ion emitted from sintering and EAF. Yu et al. (2018) investigated the correlation of CPM with $\mathrm{SO}_{2}$ concentration and indicated that CPM tended to increase as $\mathrm{SO}_{2}$ concentration increased. Li et al. (2019a) confirmed that $\mathrm{SO}_{2}$ and $\mathrm{NO}_{x}$ are primary precursors of fine PM in the environment. Thus, the removal efficiencies of $\mathrm{SO}_{2}$ and $\mathrm{NO}_{x}$ achieved with the APCDs not only affect the emissions of $\mathrm{SO}_{2}$ and $\mathrm{NO}_{x}$ but also CPM. Therefore, it is important to investigate the characteristics of air pollutants emitted from SP and EAF. Nevertheless, simultaneous sampling and analysis of $\mathrm{FPM}_{2.5}$ and CPM emissions from the steel-making process are not well documented so far.

On the other hand, the rapid expansion of global steel-making industry inevitably puts tremendous pressure on the environment. For instance, PAHs are incomplete combustion substances generated in the iron and steel-making processes. PAHs are mainly formed via pyrolysis of hydrocarbons, cyclization of chain alkanes or single-ring aromatics, condensation and polymerization of lowcarbon PAHs (Zhang et al., 2020). In the SP and EAF steel-making process, PAHs may be present in the scrap steel and are volatilized during production processes or they may form as a result of incomplete combustion of residual organic matter, fuels and additives. Wang et al. (2020) investigated $\mathrm{PM}_{2.5}$-bound PAHs in ambient air in Anshan of China during 2014-2015, indicating that the concentrations of $16 \mathrm{PAHs}$ in steel-making dust were much higher than that from other emission sources. Sintering process has long been recognized as a significant source of PAHs emissions due to the input of a large amount of coal and iron ore. According to the statistics, approximately 42 and 22 tons PAHs were emitted from sintering process per year in the USA and UK, respectively (Chen et al., 2012). In addition, previous study showed that coal combustion and steel-making dust contributed to over $86 \%$ of the total cancer risk linked to PAHs exposure (Wang et al., 2020). Hence, sintering process and electric arc furnaces have been identified as important organic pollutant sources (Odabasi et al., 2009; Amodio et al., 2013). Because PAHs are toxic and pose great adverse impact on human health and environment, numerous studies have been 
conducted to investigate PAHs emissions from iron and steel processes (Odabasi et al., 2009; Amodio et al., 2013; Van Thuong et al., 2014; Khaparde et al., 2016). In fact, 16 PAHs have been listed as the priority pollutants by the U.S. Environmental Protection Agency (U.S. EPA) and the International Agency for Research on Cancer (IARC) and classified by the latter into four categories based on mutagenicity and carcinogenicity (Yang et al., 2002). Currently, most studies on PAHs focused on the 16 PAHs prioritized for regulation by the U.S. EPA, but few studies have focused on other PAHs. The TEF values for the $11 \mathrm{PAHs}$ are relatively high, some are even higher than the $16 \mathrm{PAHs}$ regulated by U.S. EPA. PAHs may have equal numbers of rings, but the configurations and arrangements of the rings bring about differences in properties such as chemical and physical properties (Cheruiyot et al., 2015). Therefore, the European Union (EU) and the EU Scientific Committee on Food (SCF) have listed 24 and 15 PAHs, respectively, as the priority targets for control with high hazards. This study investigates 27 PAHs, including U.S. EPA, EU and SCF priority control species to better understand the characteristics of PAHs emitted from steel-making processes. On the other hand, $\mathrm{CO}$ is often considered as an indicator of incomplete combustion. Previous studies have shown that when the concentration of $\mathrm{CO}$ increases, the concentration of PAHs increases as well, indicating $\mathrm{CO}$ concentration has a strong correlation with PAHs (Blumenstock et al., 2000; Oh et al., 2007). According to the Taiwan EPA, the CO emission from the steel industry reached 188,196 ton $\mathrm{yr}^{-1}$. Based on the comprehensive emission inventory of air pollutants in China's iron and steel industry, each ton of iron and steel produced by SP and EAF generates 22,000 and 9800 grams of CO, respectively (Wang et al., 2016).

Information on the emissions of FPM $2.5, C P M$, and PAHs from SP and EAF is rather limited. In this study, the concentrations of PM (FPM 2.5 and CPM), PAHs, $\mathrm{SO}_{\mathrm{x}}, \mathrm{NO}_{\mathrm{x}}$ and $\mathrm{CO}$ at the inlet and outlet of APCDs in SP and EAF, respectively, were simultaneously measured to evaluate the APCD performance and the emission characteristics of these pollutants. In addition, emission factors of these air pollutants are calculated and unique diagnostic ratios of PAHs emitted from the steelmaking processes are identified.

\section{METHODS}

\subsection{Description of the Sampling Locations}

Concentrations of air pollutants at the inlet and outlet of APCDs in SP and EAF located in central Taiwan were measured to evaluate the performance of the APCDs adopted and the emission characteristics of the air pollutants. In the SP investigated, iron ore, flux, and recovery material are agglomerated to produce sintering ore at the capacity of 476 tons $\mathrm{h}^{-1}$, while the EAF uses scrap steel and calcium oxide as raw materials to generate steel, with the capacity of 144 tons $\mathrm{h}^{-1}$. The fuel in the SP contains coke and coking oven gas while that in EAF are natural gas and coking oven gas. The sampling locations and pollutants measured at SP and EAF are shown in Fig. 1. Dry electrostatic precipitator (DESP) is integrated with semi-dry FGD as well as SCR as APCDs for SP. The EAF is equipped with only baghouse $(\mathrm{BH})$ as APCD. In this study, the sampling location of air pollutants (PAHs, $\mathrm{NO}_{x}, \mathrm{SO}_{x}, \mathrm{CO}, \mathrm{FPM}, \mathrm{FPM}_{2.5}$, and CPM) are clearly marked in Fig 1 . On the other hand, the pollutant concentrations reported for the SP are corrected with the oxygen content of $15 \%$, while oxygen content correction is not required for EAF.

\subsection{Flue Gas Compositions Analysis}

A portable flue gas analyzer (TESTO 350, Germany) was used to measure the concentrations of $\mathrm{NO}_{x}, \mathrm{SO}_{2}, \mathrm{O}_{2}, \mathrm{CO}$, and $\mathrm{CO}_{2}$ at the inlet and outlet of the APCDs. The resolutions of $\mathrm{O}_{2}, \mathrm{CO}_{2}, \mathrm{CO}$, $\mathrm{NO}_{\mathrm{x}}$, and $\mathrm{SO}_{2}$ are 0.01 vol.\%, 0.01 vol.\%, $1.0 \mathrm{ppm}, 0.1 \mathrm{ppm}$, and $0.1 \mathrm{ppm}$, respectively. The analyzer was calibrated with standard gases before sampling. The PM and water vapor were firstly removed through the filter and water vapor removal devices, respectively, and the flue gas was subsequently introduced into the gas analyzer for analysis. On the other hand, the data of $\mathrm{NH}_{3}$ concentrations emitted were provided by the plant based on the routine measurement.

\subsection{FPM 2.5 and CPM Sampling and Analysis}

$\mathrm{FPM}_{2.5}$ was measured based on the U.S. EPA method 201A (Determination of $\mathrm{PM}_{10}$ and $\mathrm{PM}_{2.5}$ emissions from stationary sources) while U.S. EPA method 202 (the dry impingers method for 


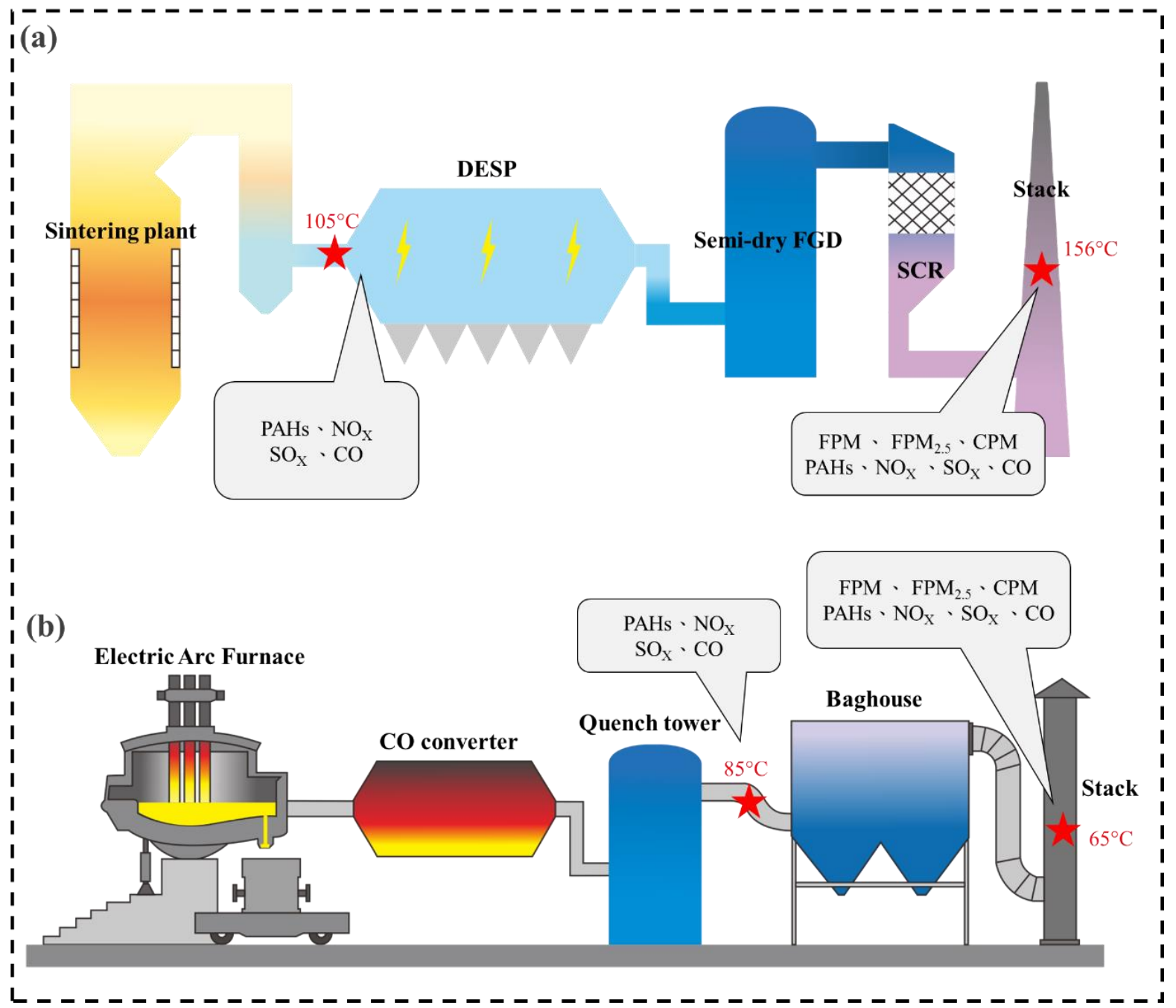

Fig. 1. Sampling locations of the (a) SP and (b) EAF.

determining condensable particulate emissions from stationary sources) was applied for CPM measurement. Fig. 2(a) shows the sampling train for $\mathrm{FPM}_{2.5}$ and CPM measurements. Before sampling, the flow rate should be estimated to meet the isokinetic principle; and appropriate front nozzle for sampling the flue gas must then be selected. The gas stream passed through a $\mathrm{PM}_{2.5}$ cyclone to remove the PM with the aerodynamic diameter greater than $2.5 \mu \mathrm{m}$ and $\mathrm{PM}_{2.5}$ were collected on a $47 \mathrm{~mm}$ quartz filter (Tissuquartz, 2500 QAT-UP). The filter was conditioned at a relative humidity of $30-40 \%$ and temperature of $20-23^{\circ} \mathrm{C}$ for $24 \mathrm{~h}$ before and after sampling.

In this study, the FPM 2.5 and CPM sampling devices were connected in series for simultaneous sampling of $\mathrm{FPM}_{2.5}$ and CPM. After the collection of $\mathrm{FPM}_{2.5}$ with a $47 \mathrm{~mm}$ quartz filter, the gas stream passed through a condenser; and CPM was subsequently collected in the water dropout impinger, the modified Greenburg Smith impinger and CPM filter (Advantec, J020A090C PTFE). After sampling, the impinger and CPM filter were immediately purged with ultra-high purity nitrogen for $1 \mathrm{~h}$ to remove the dissolved sulfur dioxide. Deionized water and $\mathrm{n}$-hexane were used to rinse the whole samples for obtaining inorganic (water soluble) and organic (organic solvent soluble) fractions of CPM, which were dried and weighed in the laboratory. The summation of these two fractions results in CPM concentration.

\subsection{PAH Sampling and Analysis}

The U.S. EPA Method 23A was applied for sampling PAHs and Fig. 2(b) shows the PAH sampling train which includes a front nozzle, a stainless probe, a filter holder, a condenser, an XAD-2 adsorbent and an impinger. The flue gas containing PAHs was sampled and passed through a 


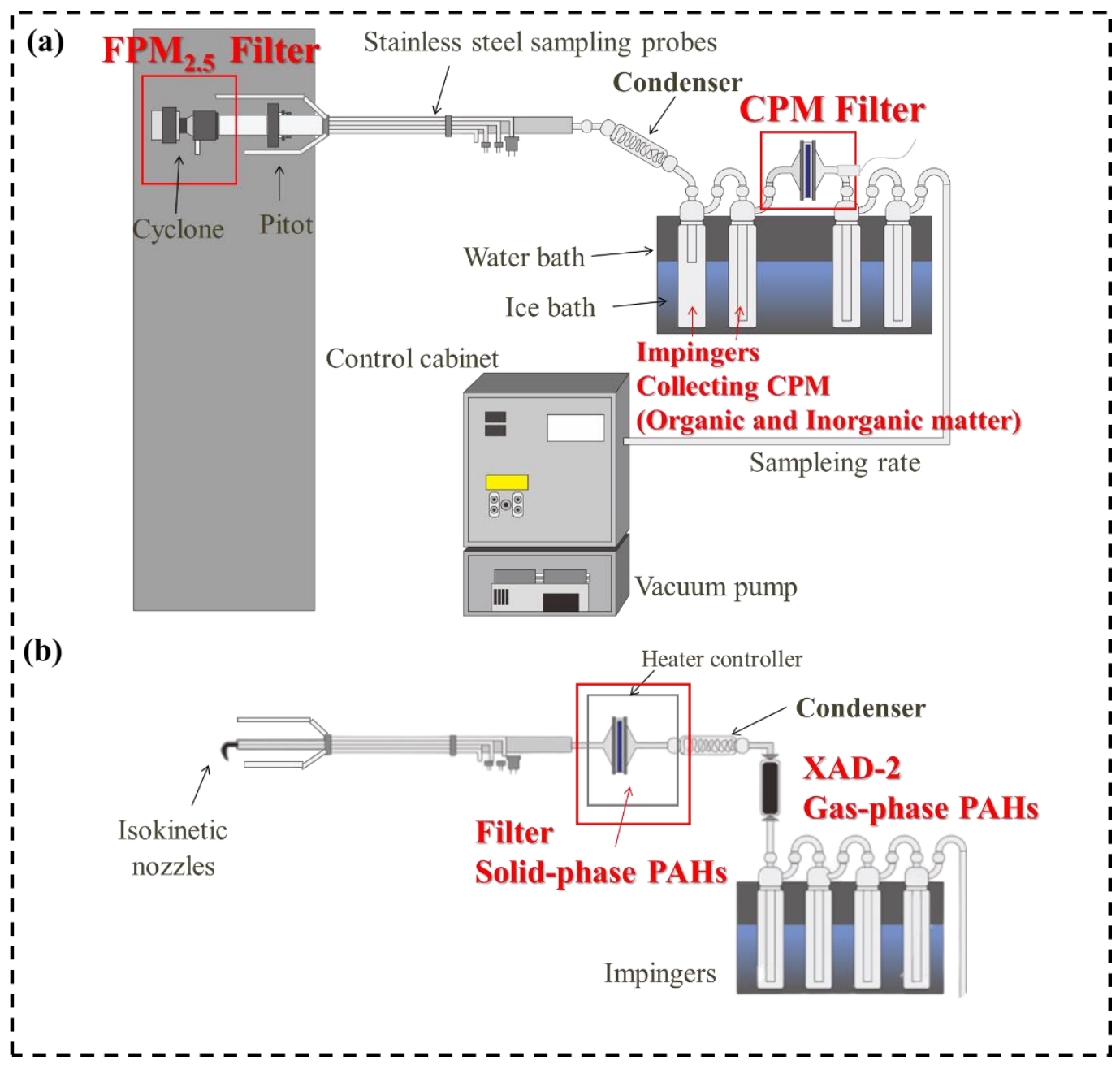

Fig. 2. Sampling train of (a) $\mathrm{FPM}_{2.5}$ and CPM (U.S. EPA Method $202 \mathrm{~A}$ ), and (b) PAHs (U.S. EPA Method 23A).

heated filter holder packed with a $90 \mathrm{~mm}$ quartz filter (Tissuquartz, 2500 QAT-UP) to collect FPM and solid-phase PAHs, and through a condenser to capture the remaining gas-phase PAHs with XAD-2. Next, the filter containing solid-phase PAHs and the XAD-2 resin containing gas-phase PAHs were extracted with dichloromethane (Fisher, 99.9\%) for $22 \pm 2 \mathrm{~h}$ using the Soxhlet extraction process. Before the extraction process, an isotope-spiked solution of PAHs was added into the samples to quantify the PAH concentration. The extraction solution was then concentrated to $2 \mathrm{~mL}$ using a rotary evaporator at $45^{\circ} \mathrm{C}$ and then replaced by $8 \mathrm{~mL}$ hexane, which was purified with a silica gel cleanup procedure. These samples were later analyzed using a gas chromatography/mass spectrometry (GC/MS) (Thermo Fisher Scientific, Double Focusing Sector Mass Spectrometer) with a fused silica capillary column DB-5 MS (60 $\mathrm{m} \times 0.25 \mathrm{~mm} \times 0.25 \mu \mathrm{m})$ under selected ion monitoring (SIM) mode conditions. The 27 PAHs containing 16 U.S. EPA PAHs, 15 EU PAHs, and three additional PAHs are analyzed in this study. Detailed information regarding the physical and chemical properties and the toxic equivalency factors (TEFs) of 27 PAHs analyzed are presented in Table S1. The TEFs are used to calculate the toxic equivalent (TEQ) concentration of 27 PAHs and assess the carcinogenic risk of PAHs. The TEF is based on the toxicity of BaP. The calculation is described as follows:

$B a P_{e q}=\sum_{n}^{i} P A H_{i} \times T E F_{i}$

where $P A H_{i}$ is the concentration of the individual PAH in each sample, and $T E F_{i}$ is the TEF of the individual PAH. 
The PAH concentrations were calculated using a group of six concentration levels ranging from 0.01 to $1 \mu \mathrm{g} \mathrm{mL}$. The calibration curves were linear in the concentration ranges, with the correlation coefficient $\left(R^{2}\right)$ of 0.995 . The method detection limits of the 27 PAHs analyzed were determined from the lowest standard in the calibration curve. The mean recovery rate of the 27 PAHs analyzed ranged from $66 \%$ to $77 \%$.

\subsection{Emission Factor}

The emission factor (EF) is used to estimate the pollutant emissions and is defined as the pollutants emitted to the atmosphere by industrial activity of the emission source. The calculation is described as follows,

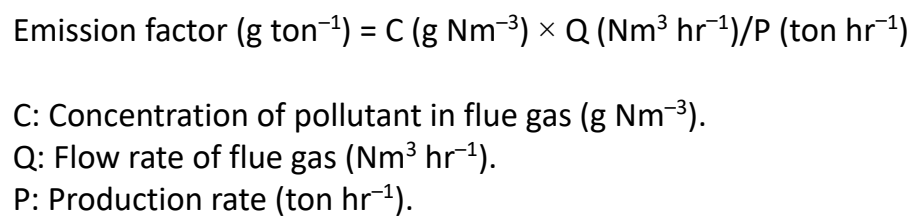

\section{RESULTS AND DISCUSSION}

\subsection{Flue Gas Compositions}

Table 1 shows the flue gas compositions measured at the inlet of APCD (DESP + FGD + SCR) and the stack of SP, respectively. The moisture, oxygen, and $\mathrm{CO}_{2}$ contents measured at the SP stack are $20 \%, 13.9 \%$, and $7.2 \%$, respectively, which are close to that measured at the APCD inlet. Moreover, the CO concentrations measured at the APCD inlet and stack are 5,857 and 5,208 ppm, respectively, confirming that $\mathrm{CO}$ removal achieved with existing APCDs is insignificant. The flue gas compositions in the baghouse inlet and stack of EAF are also provided in Table 1 . The concentrations of $\mathrm{CO}_{2}$ and $\mathrm{CO}$ in the EAF stack are measured as $1.0 \%$ and $191 \mathrm{ppm}$, respectively. Sintering process agglomerates iron ore material with other recycle material such as ESP ash at high temperatures. Materials containing oily reductants (aliphatic hydrocarbons and aromatic hydrocarbons) and carbonaceous by-products are mixed, and varieties of pollutants may be generated during sintering process. The feeding material of electric arc furnace was mainly scrap steel while graphite electrode was applied to provide the heat to melt scrap steel. Although the EAF steel-making is a high temperature process, liquid oxygen was applied in the furnace and $\mathrm{NO}_{x}$ generation was insignificant. Moreover, even though the scrap steel contained small amounts of chlorine and sulfur, which were neutralized by the limestone added in the furnace. The quench tower adopted by $\mathrm{EAF}$ also helped remove $\mathrm{SO}_{\mathrm{x}}$ and $\mathrm{HCl}$. Thus, $\mathrm{NO}_{\mathrm{x}}, \mathrm{SO}_{\mathrm{x}}$ and $\mathrm{HCl}$ concentrations measured at the $\mathrm{BH}$ inlet and stack of the EAF were relatively low compared to the sintering process. However, SP and EAF used petroleum coke and clean natural gas as fuel, respectively,

Table 1. Flue gas compositions of the SP and EAF.

\begin{tabular}{|c|c|c|c|c|}
\hline \multirow{2}{*}{ Locations } & \multicolumn{2}{|c|}{ SP } & \multicolumn{2}{|c|}{ EAF } \\
\hline & ${ }^{*} \mathrm{APCD}$ inlet & Stack & $\mathrm{BH}$ inlet & Stack \\
\hline Flue gas temperature $\left({ }^{\circ} \mathrm{C}\right)$ & 105 & 156 & 85 & 65 \\
\hline $\mathrm{H}_{2} \mathrm{O}(\%)$ & 18 & 20 & 4.0 & 3.0 \\
\hline $\mathrm{O}_{2}(\%)$ & 12.7 & 13.9 & 20.4 & 20.5 \\
\hline $\mathrm{CO}(\mathrm{ppm})$ & 5857 & 5208 & 195 & 191 \\
\hline $\mathrm{CO}_{2}(\%)$ & 7.4 & 7.2 & 1.0 & 1.0 \\
\hline $\mathrm{NO}_{\mathrm{x}}(\mathrm{ppm})$ & 102 & 43 & $<1$ & $<1$ \\
\hline $\mathrm{SO}_{2}(\mathrm{ppm})$ & 96 & 17 & $<1$ & $<1$ \\
\hline $\mathrm{HCl}(p p m)$ & $<0.1$ & $<0.1$ & $<0.1$ & $<0.1$ \\
\hline $\mathrm{NH}_{3}(\mathrm{ppm})$ & *- & 2.4 & $*$ & *- \\
\hline
\end{tabular}

${ }^{*}$ APCD: air pollution control device (DESP + FGD + SCR).

*-: Not sampled. 
resulting in much higher $\mathrm{CO}_{2}$ and $\mathrm{CO}$ emissions from $\mathrm{SP}$ than that from EAF. Moreover, EAF is equipped with a $\mathrm{CO}$ converter at the back end of the combustion outlet to reduce $\mathrm{CO}$ emissions. Hence, additional control device for reducing $\mathrm{CO}$ emitted from SP should be considered.

Based on the concentrations of $\mathrm{NO}_{x}$ and $\mathrm{SO}_{2}$ measured (Table 1), the removal efficiencies of $\mathrm{NO}_{x}$ and $\mathrm{SO}_{2}$ achieved with the APCDs (DESP + FGD + SCR) of SP are $58 \%$ and $82 \%$, respectively. Surprisingly, the $\mathrm{NO}_{x}$ removal achieved with $\mathrm{SCR}$ is much lower than the original design value of 80\% (Busca et al., 1998; Heck et al., 2016). Overall, the SCR performance depends on the operating parameters including temperature, $\mathrm{NH}_{3} / \mathrm{NO}_{x}$ ratio, and catalyst activity. If the operating temperature of SCR is not appropriate, $\mathrm{NH}_{3}$ would escape from the reactor or even start to oxidize, resulting in lower $\mathrm{NO}_{x}$ removal efficiency. In addition, inappropriate $\mathrm{NH}_{3} / \mathrm{NO}_{x}$ ratio also affects $\mathrm{NOx}$ removal efficiency. On the other hand, $\mathrm{SO}_{3}$ reacts with water vapor present in flue gas and with ammonia injected to form sulfuric acid and ammonium sulfate, respectively. Ammonium sulfate may deposit and accumulate onto the catalyst, reducing the catalytic activity. Table 1 verifies that the concentrations of $\mathrm{NO}_{x}$ and $\mathrm{SO}_{2}$ measured at the baghouse inlet of EAF are lower than $1 \mathrm{ppm}$. Although $\mathrm{SO}_{2}$ might be also formed by the reaction of sulfur from the scrap steel and oxygen from the air; $\mathrm{SO}_{2}$ generated could be captured by the limestone which is one of the raw materials in the EAF. Consequently, with no additional desulfurization and de-NO $\mathrm{N}_{\mathrm{x}}$ devices, the emissions of $\mathrm{NO}_{x}$ and $\mathrm{SO}_{2}$ from EAFs meet the emission standards.

Heck et al. (2016) investigated the correlation among $\mathrm{NO}_{x}$ conversion, operating temperature, $\mathrm{NH}_{3} / \mathrm{NO}_{\mathrm{x}}$ ratio, and ammonia slip of an $\mathrm{SCR}$, indicating that more than $95 \% \mathrm{NO}_{\mathrm{x}}$ conversion was obtained when operated at $360^{\circ} \mathrm{C}$ and $\left[\mathrm{NH}_{3}\right] /[\mathrm{NO}]$ of 1.0 , and the ammonia slip decreases with increasing operating temperature. The $\mathrm{NO}_{x}$ removal efficiency achieved with SCR of the SP was $58 \%$, indicating the SCR performance is not as expected and can be improved. The $\mathrm{NH}_{3}$ slip at the SP stack was measured as $2.4 \mathrm{ppm}$, which is lower than the original design value of $10 \mathrm{ppm}$. However, the amount of $\mathrm{NH}_{3}$ emitted is significant about $1.5 \mathrm{~kg} \mathrm{hr}^{-1}$ due to the large flow rate of flue gas $\left(805,626 \mathrm{Nm}^{3} \mathrm{hr}^{-1}\right)$. To minimize $\mathrm{NH}_{3}$ slip, $\left[\mathrm{NH}_{3}\right] /[\mathrm{NO}]$ ratio is typically controlled at the range of 0.9-1 to provide satisfactory $\mathrm{NO}_{x}$ conversions (Crolla, 2015). The operating conditions of the SCR adopted by SP should be optimized since $\mathrm{NO}_{x}$ and $\mathrm{NH}_{3}$ are primary precursors of $\mathrm{PM}_{2.5}$ and CPM.

\subsection{Mass Concentrations of FPM, FPM 2.5, and CPM in Stack Exhaust}

As shown in Fig 3, the FPM concentrations measured at the stacks of SP and EAF are $8.2 \pm$ $1.3 \mathrm{mg} \mathrm{Nm}^{-3}$ and $13.6 \pm 2.2 \mathrm{mg} \mathrm{Nm}^{-3}$, respectively, indicating that both ESP and baghouses are in good operating conditions for controlling FPM generated in steel-making processes.

Additionally, $\mathrm{FPM}_{2.5}$ emitted from the SP is measured as $1.8 \pm 0.5 \mathrm{mg} \mathrm{Nm}^{-3}$, which is lower than that emitted from EAF $\left(3.2 \pm 1.1 \mathrm{mg} \mathrm{Nm}^{-3}\right)$. Emission of $\mathrm{FPM}_{2.5}$ depends on the type and operating conditions of the APCDs adopted. SCR is the last air pollution control device in the SP. In order to

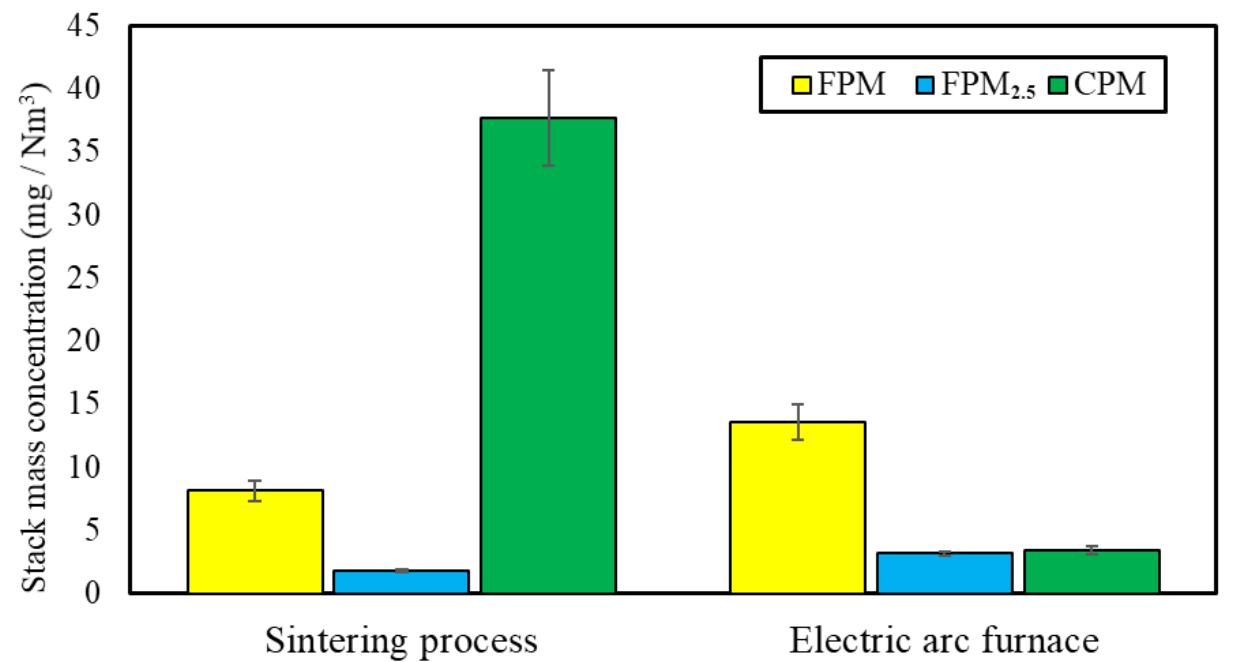

Fig. 3. Concentrations of FPM, $\mathrm{FPM}_{2.5}$, and CPM emitted from two steel-making processes. 
avoid plugging of the catalyst, additional $\mathrm{BH}$ is installed at downstream of the semi-dry FGD to capture PM. It is also the main reason why PM emissions from SP are lower than that of EAF.

Fig 3 indicates that CPM concentrations emitted from SP and EAF are $37.7 \pm 1.3 \mathrm{mg} \mathrm{Nm}^{-3}$ and $3.4 \pm 0.8 \mathrm{mg} \mathrm{Nm}^{-3}$, respectively. The CPM emitted is relevant to the type and operating conditions of APCDs adopted, exhaust temperature, and gas-phase pollutants including $\mathrm{SO}_{2}, \mathrm{NO}_{x}$, and $\mathrm{NH}_{3}$ (Yang et al., 2015; Li et al., 2019a; Yu et al., 2018; Gong et al., 2016). Li et al. (2019b) indicate that low-low temperature electrostatic precipitator (LLT-ESP) provides a good removal efficiency of $\mathrm{CPM}(>77 \%)$. For SP, the SCR needs to be reheated to $280^{\circ} \mathrm{C}$ to remove $\mathrm{NO}_{\mathrm{x}}$, resulting in a stack exhaust temperature above $156^{\circ} \mathrm{C}$ (Table 1 ), which is unfavorable for removing CPM. Moreover, SP emits much higher concentrations of $\mathrm{SO}_{2}, \mathrm{NO}_{x}$, and $\mathrm{NH}_{3}$ if compared with $\mathrm{EAF}$ (Table 1), resulting in higher CPM emissions. Therefore, the $\mathrm{SO}_{2}, \mathrm{NO}_{x}$, and $\mathrm{NH}_{3}$ concentrations emitted from the SP stack and the temperature of the stack exhaust should be lowered to reduce CPM emissions.

\subsection{Emission Characteristics of PAHs from Two Steel-making Processes}

\subsubsection{Mass concentrations of PAHs}

This study sampled and analyzed gas-phase and solid-phase concentrations of $27 \mathrm{PAHs}$ at the ESP inlet and stack of the SP and at the baghouse inlet and stack of the EAF, respectively, to explore $\mathrm{PAH}$ formation potential and emission characteristics from these two steel-making processes. The total PAH concentrations in the flue gas of the SP and EAF are shown in Table 2. The results indicate that the concentration of PAHs at ESP inlet of the SP is $226 \mu \mathrm{g} \mathrm{Nm}^{-3}$, and is reduced to $63 \mu \mathrm{g} \mathrm{Nm}^{-3}$ by APCDs (DESP + FGD + SCR). The overall PAH removal efficiency achieved with the APCDs is $72 \%$. Additionally, the results show that removal efficiencies of gas-phase and solid-phase PAHs achieved with the APCDs are $72 \%$ and $87 \%$, respectively.

The PAHs concentration measured at the baghouse inlet of the EAF is $182 \mu \mathrm{g} \mathrm{Nm}^{-3}$ and is reduced to $136 \mu \mathrm{g} \mathrm{Nm}^{-3}$ at the stack. The overall removal efficiency of PAHs achieved with baghouse (26\%) is relatively low. To be specific, the removal efficiencies of gas-phase and solidphase PAHs achieved are $23 \%$ and $81 \%$, respectively (Table 2 ). The baghouse reveals a high removal efficiency for solid-phase PAHs but is not effective in removing gas-phase PAHs.

Moreover, Yang et al. (2002) studied 21 PAHs concentration emitted from steel-making industry (including SP and EAF) and the results showed that the PAHs emitted from the SP and EAF are $778-1,360 \mu \mathrm{g} \mathrm{Nm}^{-3}$ and $910 \mu \mathrm{g} \mathrm{Nm}^{-3}$, respectively. The results indicated that in addition to the $16 \mathrm{PAH}$ priority species regulated by the U.S. EPA, emission of other $11 \mathrm{PAHs}$ species also deserves further discussion.

On the other hand, the concentrations of PAHs emitted from steel-making processes are significantly higher than those emitted from coal-fired boilers (Li et al., 2016; Lu et al., 2019). Oh et al. (2007) investigated the characteristics of air pollutants emitted from municipal solid waste incinerator, and indicate that high $\mathrm{CO}$ concentration during bad operating conditions is closely related with PAHs concentrations ( $\mathrm{R}>0.77$ ). Blumenstock et al. (2000) reported the increase of $\mathrm{PAHs}$ during incinerator malfunctions and that PAH formation was well correlated with $\mathrm{CO}$. Hence, more attention should be given to the emissions of $\mathrm{CO}$ from steel-making processes, which affects PAHs emissions.

Table 2. Concentrations and removal efficiencies of gas- and solid -phase PAHs in the SP and EAF

\begin{tabular}{|c|c|c|c|c|c|c|c|c|}
\hline \multirow{3}{*}{ PAHs } & \multicolumn{4}{|c|}{ SP } & \multicolumn{4}{|c|}{ EAF } \\
\hline & \multirow{2}{*}{ 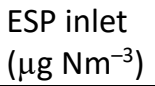 } & \multirow{2}{*}{$\begin{array}{l}\text { Stack } \\
\left(\mu \mathrm{g} \mathrm{Nm}^{-3}\right)\end{array}$} & \multicolumn{2}{|c|}{ Removal efficiency } & \multirow{2}{*}{$\begin{array}{l}\text { Baghouse inlet } \\
\left(\mu \mathrm{g} \mathrm{Nm}^{-3}\right)\end{array}$} & \multirow{2}{*}{$\begin{array}{l}\text { Stack } \\
\left(\mu \mathrm{g} \mathrm{Nm}^{-3}\right)\end{array}$} & \multicolumn{2}{|c|}{ Removal efficiency } \\
\hline & & & Mass conc. $(\%)$ & TEQ conc. (\%) & & & Mass conc. $(\%)$ & TEQ conc. (\%) \\
\hline Gas-phase & $\begin{array}{l}218 \\
(96 \% *)\end{array}$ & $\begin{array}{l}62 \\
(98 \% *)\end{array}$ & 72 & 80 & $\begin{array}{l}173 \\
(95 \% *)\end{array}$ & $\begin{array}{l}134 \\
(99 \% *)\end{array}$ & 23 & 65 \\
\hline Solid-phase & $\begin{array}{l}8 \\
(4 \% *)\end{array}$ & $\begin{array}{l}1 \\
(2 \% *)\end{array}$ & 87 & 38 & $\begin{array}{l}9 \\
(5 \% *)\end{array}$ & $\begin{array}{l}2 \\
(1 \% *)\end{array}$ & 81 & 90 \\
\hline Total & $\begin{array}{l}226 \\
(100 \% *)\end{array}$ & $\begin{array}{l}63 \\
(100 \% *)\end{array}$ & 72 & 76 & $\begin{array}{l}182 \\
(100 \% *)\end{array}$ & $\begin{array}{l}136 \\
(100 \% *)\end{array}$ & 25 & 68 \\
\hline
\end{tabular}

conc.: concentration.

* PAHs contribution of gas and particulate PAHs to total PAHs (\%). 


\subsubsection{Distributions of gas-phase and solid-phase PAHs}

This study also explores the distributions of gas-phase and solid-phase PAHs in the flue gases of two steel-making processes. As shown in Table 2, the distribution of gas-phase PAHs increased from $96 \%$ to $98 \%$ as flue gas passed through the APCDs of SP. The gas-phase PAHs concentration is much higher than the solid-phase PAHs concentration. The results also indicate that the APCDs adopted by the SP had a higher removal efficiency for solid-phase PAHs (87\%) compared with gasphase PAHs (72\%). Fig. 4(a) shows the distributions of gas-phase and solid-phase PAHs with different numbers of ring at the ESP inlet and stack of the SP, respectively. The results indicate that gasphase PAHs at the ESP inlet are primarily composed of LMW (light-molecular-weight, 2-3 ring) PAHs (95\%); PAHs with MMW (medium-molecular-weight, 4-ring) and HMW (high-molecularweight, 5-6 ring) accounts for $4 \%$ and $1 \%$, respectively. On the other hand, the solid-phase PAHs are primarily composed of MMW and HMW PAHs (81\%), accounting for $14 \%$ and $67 \%$, respectively. The 2-ring and 3-ring accounts only for $6 \%$ and $13 \%$, respectively. As the flue gas passed through the APCDs, distribution of LMW PAHs decreased to 93\% and the MMW PAHs increased to $6 \%$. However, the LMW PAHs remained as the dominant species. In addition, the contribution of HMW PAHs in solid phase is decreased significantly from $67 \%$ to $20 \%$. The 2-ring PAHs decreased from $6 \%$ to $1 \%$, and the major increases are 3-ring and 4-ring $\mathrm{PAHs}$, which increase from $13 \%$ to $22 \%$ and $14 \%$ to $58 \%$, respectively. Li et al. (2015) studied the impact of SCR on PM 2.5 emissions from coal-fired power plants and the results showed that PAHs formed within the SCR may adsorb on the particles. The overall results showed that existing APCD cannot effectively remove gasphase PAHs, particularly the 2-4 ring gas-phase PAHs. For solid-phase PAHs, after passing through the SCR, the percentage of 3-4 ring PAHs in solid phase increased significantly in the SP stack.

Table 2 shows the distributions of gas-phase and solid-phase PAHs at the baghouse inlet and stack of the EAF. The gas-phase and solid-phase PAHs at the baghouse inlet of EAF accounted for $95 \%$ and $5 \%$, respectively. As the flue gas passed through the baghouse, distributions of gas-phase PAHs increased to $99 \%$. The concentration of gas-phase at the baghouse inlet and stack are much higher than that of solid-phase PAHs. In addition, the EAF treats the flue gas with baghouse only. Thus, the baghouse had a good removal efficiency for solid-phase PAHs but did not effectively remove gas-phase PAHs. Fig. 4(b) shows the distributions of gas-phase and solid-phase PAHs with different numbers of rings at the baghouse inlet and stack of the EAF, respectively. The results show that most (89\%) PAHs at the baghouse inlet are 2-3 ring while the 4-6 ring PAHs account for $11 \%$. The solid-phase PAHs are primarily composed of $4-6$ ring PAHs (91\%) and the 2-3 ring PAHs contribute only $9 \%$. As the flue gas passes through the baghouse, the $4-5$ ring solid-phase

(a)

(b)

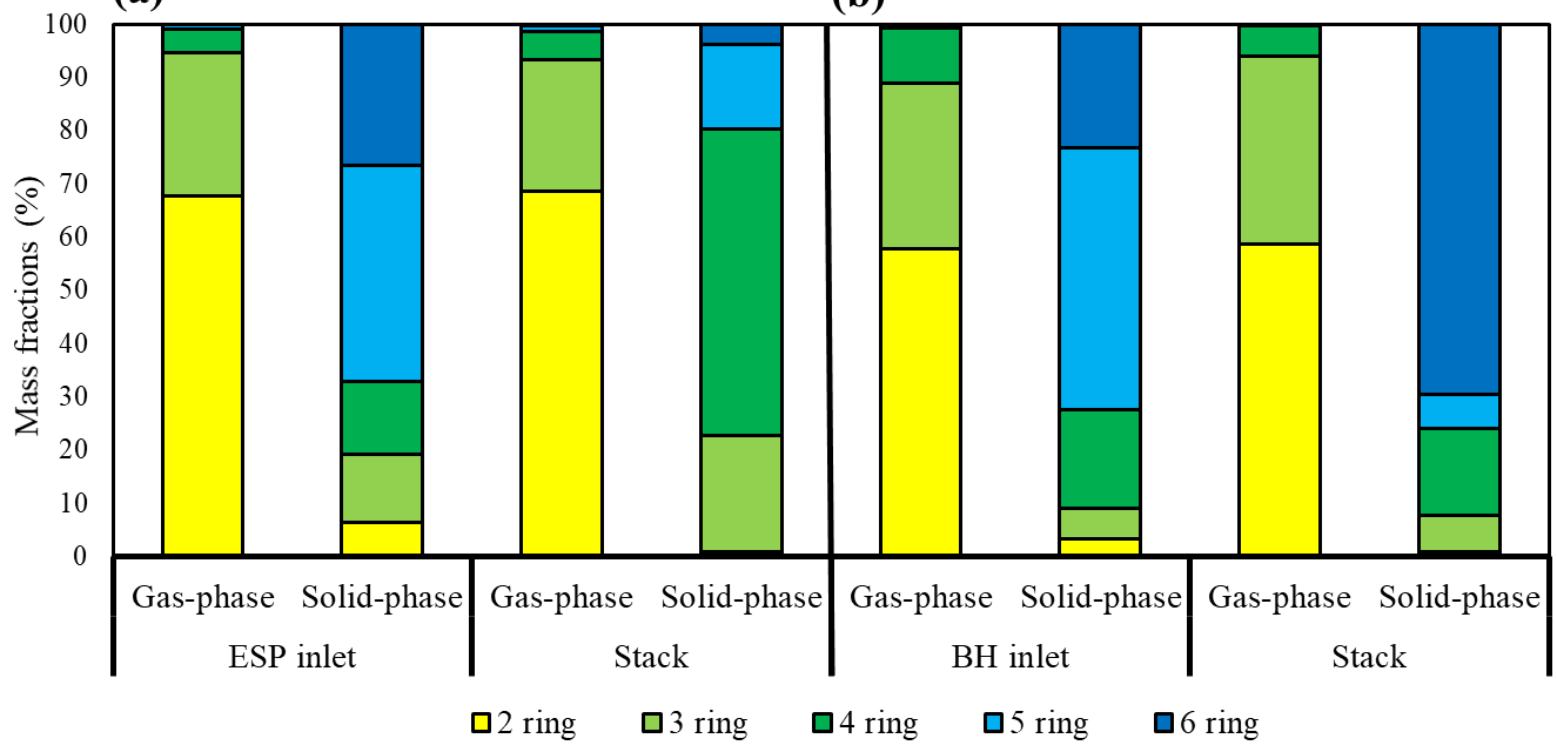

Fig. 4. Distribution of solid and gas phase PAHs species with different numbers of aromatic rings in the flue gas of (a) SP and (b) EAF. 
PAHs are effectively captured and removed by the baghouse, and the contribution decreases from $68 \%$ to $23 \%$. On the other hamd, 6-ring PAHs is significantly increased from $23 \%$ to $70 \%$. Wang et al. (2018) noted that some gas-phase PAHs may be transformed into solid-phase PAHs within the baghouse. Distribution of gas-phase and solid-phase PAHs is not in equilibrium because the solidphase PAHs with 4-6 ring can be removed with particles, whereas gas-phase PAHs with 2-3 ring are of high concentrations and are difficult to remove by baghouse (Yang et al., 2002). Zhao et al. (2014) studies the fine particle emission from a coal-fired boiler equipped with a baghouse, and the result shows that the size-classified removal efficiency of $\mathrm{PM}_{2.5}$ through the baghouse is of the lowest removal efficiency at 0.1 to $1 \mu \mathrm{m}$. In addition, the pulse blowing of the baghouse can reduce the thickness of the cake on the baghouse, hence, diminish the effectiveness of the baghouse in removing fine particles. Zhang et al. (2020) studies the size distribution of particulate PAHs in combustion source and ambient air, and the results show that 3-4 ring PAHs preferentially accumulate in coarse particles, while 5-6 ring congeners tend to be strongly adsorbed on fine particles. These studies indicate that the baghouse may increase the distribution of 6-ring PAHs.

\subsubsection{Species and TEQ of PAHs}

Fig. 5(a) shows the distribution of 27 PAHs species measured at the ESP inlet and stack of the
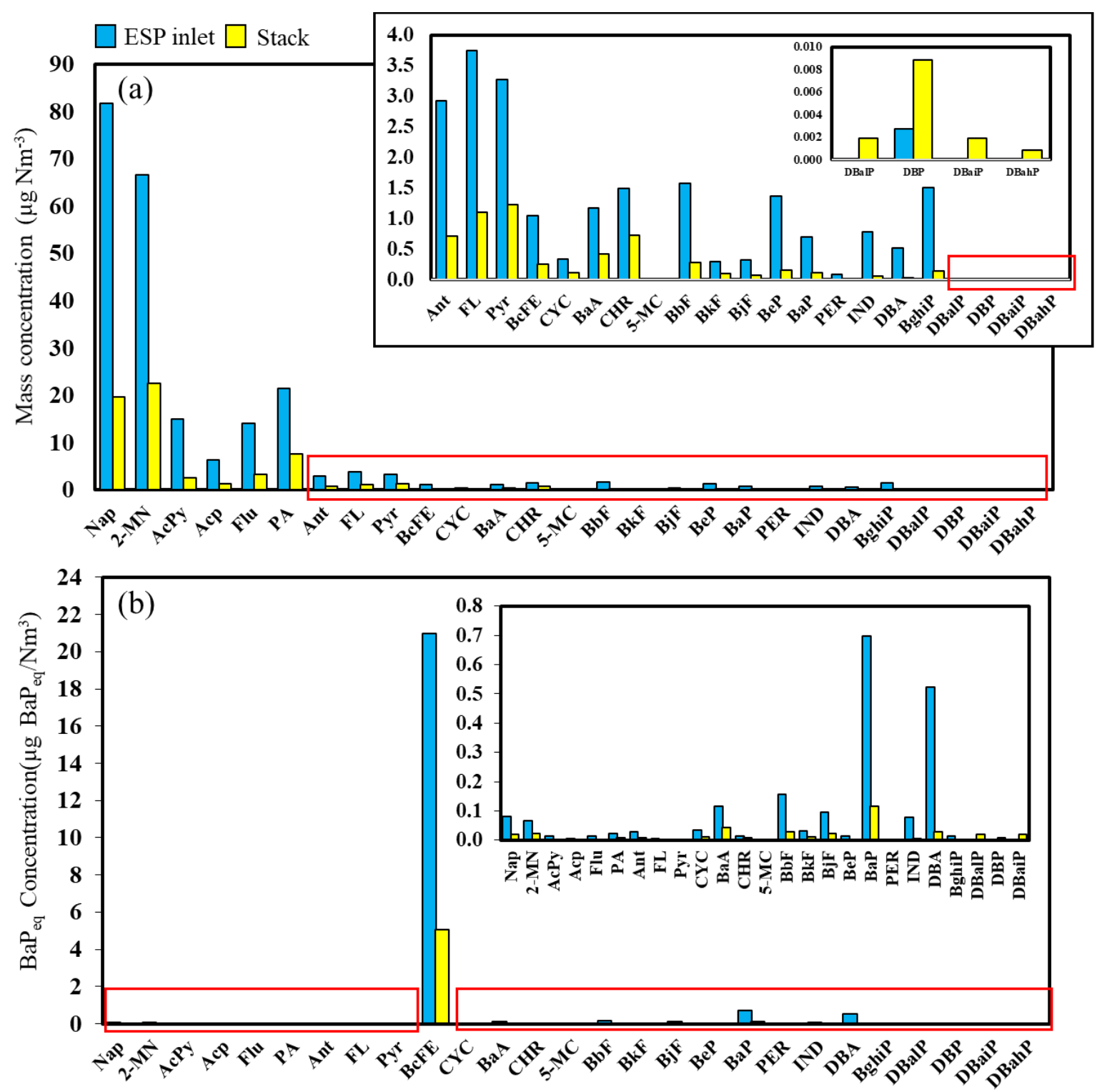

Fig. 5. Distribution of 27 (a) PAHs species and (b)TEQ concentrations ( $B a P_{\text {eq }}$ ) at ESP inlet and stack of the SP. 
SP, respectively. The results indicate that the PAHs measured at the ESP inlet and stack are primarily composed of 2-4 ring PAHs, and naphthalene is of the highest concentration. Specifically, Nap concentrations measured at the ESP inlet and stack are 81.7 and $19.7 \mu \mathrm{g} \mathrm{Nm}^{-3}$, respectively. The second and third highest contributing PAH species measured the ESP inlet and stack are 2-MN (66.6 and $22.6 \mu \mathrm{g} \mathrm{Nm}^{-3}$, respectively) and PA (21.5 and $7.65 \mu \mathrm{g} \mathrm{Nm}^{-3}$, respectively). The results are similar to the data reported by Yang et al. (2002). After passing through APCDs, distribution of PAH species did not show significant variation because dominant 2-3 ring PAHs mainly exist in gas-phase and they are difficult to remove with existing APCDs. However, some 6-ring PAHs (DBalP, DBP, DBaiP, and DBahP) species reveal increasing trend.

Additionally, the TEFs of different PAH species are used to calculate PAH TEQ concentrations $\left(\mathrm{BaP}_{\text {eq }}\right.$ ) (Fig. 6(b)). The total TEQ concentrations of PAHs measured at the ESP inlet and stack exhaust of the SP are 23.0 and $5.45 \mu \mathrm{g}-\mathrm{BaP}_{\mathrm{eq} \mathrm{Nm}}{ }^{-3}$, respectively. The overall removal efficiency of the $\mathrm{BaP}_{\text {eq }}$ achieved with the APCDs (DESP + FGD + SCR) is 76\%. The primary contributing species for the $\mathrm{BaP}_{\text {eq }}$ concentrations at the ESP inlet and stack are BcFE (21 and $5.1 \mu \mathrm{g}-\mathrm{BaP}_{\text {eq }} \mathrm{Nm}^{-3}$, respectively) and $\mathrm{BaP}\left(0.70\right.$ and $0.11 \mu \mathrm{g}-\mathrm{BaP}_{\text {eq }} \mathrm{Nm}^{-3}$, respectively).

Fig. 6(a) shows the distributions of 27 PAHs species at the baghouse inlet and stack of the EAF, respectively. The results are similar to those of the SP and 2-4 ring PAH species dominate in the
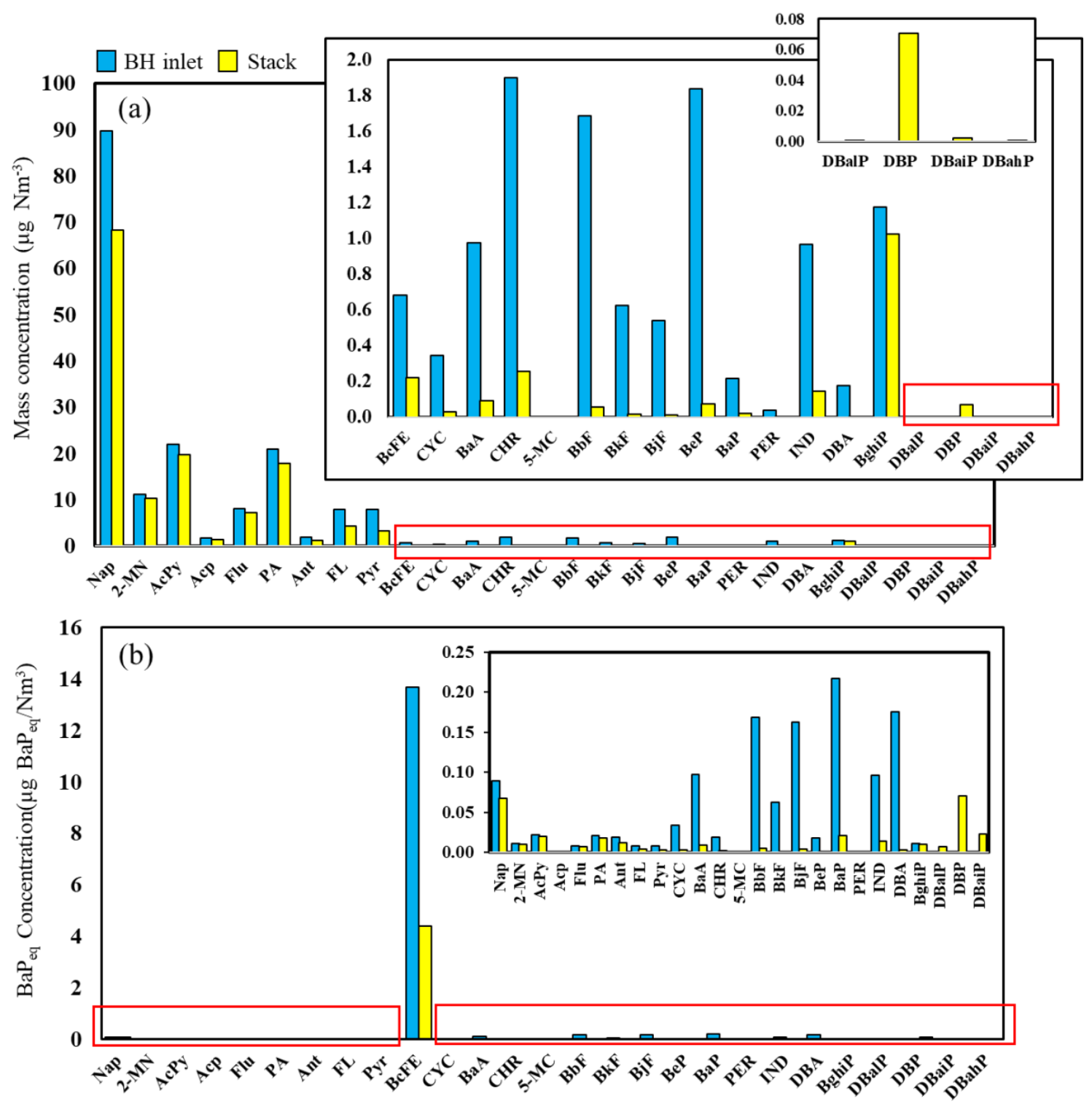

Fig. 6. Distribution of 27 (a) PAHs species and (b)TEQ concentrations $\left(\mathrm{BaP}_{\text {eq }}\right)$ at the baghouse inlet and stack of the EAF. 
gas streams of EAF. The concentrations of $\mathrm{Nap}\left(89.7\right.$ and $68.2 \mu \mathrm{g} \mathrm{Nm}^{-3}$ ) are the highest, followed by AcPy (21.9 and $19.8 \mu \mathrm{g} \mathrm{Nm}^{-3}$ ), and PA (21.0 and $17.9 \mu \mathrm{g} \mathrm{Nm}^{-3}$ ) measured the baghouse inlet and stack, respectively. After passing through the baghouse, the concentrations of 5-6 ring PAHs are significantly reduced since most 5-6 ring PAHs are present in the solid phase and could be effectively captured by baghouse, while the removal efficiency of gas-phase PAHs is not significant. Nevertheless, the pulse blowing effect caused by the baghouse clearing reduces the removal efficiency of fine particles (Zhao et al., 2014), resulting to the an increase in the distribution of HMW PAHs (BghiP, DBalP, DBP, DBaiP, and DBahP) in the flue gas stream after baghouse.

Fig. 6(b) shows that the $\mathrm{BaP}_{\text {eq }}$ concentrations measured at the baghouse inlet and stack of the EAF are 14.9 and $4.74 \mu \mathrm{g}-\mathrm{BaP}_{\text {eq }} \mathrm{Nm}^{-3}$, respectively. The overall removal efficiency of TEQ achieved with the baghouse is $68 \%$. The primary contributing species for the $\mathrm{BaP}_{\text {eq }}$ at the baghouse inlet and stack exhaust are BcFE (13.7 and $4.41 \mu \mathrm{g}-\mathrm{BaP}_{\text {eq }} \mathrm{Nm}^{-3}$, respectively) and $\mathrm{BaP}(0.21$ and 0.02 $\mu \mathrm{g}-\mathrm{BaP}_{\text {eq }} \mathrm{Nm}^{-3}$, respectively). The contribution of BcFE is significantly higher than other species due to its high TEF value (30).

Table 2 compares the removal efficiencies of PAHs based on mass and TEQ concentrations of the SP and EAF, respectively. The results show that the removal efficiencies of solid-phase PAHs concentrations and PAH TEQ achieved with the existing APCDs (DESP + FGD + SCR) of SP are 87\% and $38 \%$, respectively. On the other hand, the removal efficiencies of solid-phase PAH concentrations and PAH TEQ achieved with the baghouse of the EAF are $81 \%$ and $90 \%$, respectively. The comparison shows that the APCDs adopted by SP have a higher removal efficiency of solid-phase PAHs concentration than that of EAF, but the removal efficiency of solid-phase $\mathrm{BaP}_{\text {eq }}$ is much lower than that of EAF. Due to varying combinations of APCDs in the two steelmaking procedures, the removal efficiencies of pollutants achieved are different. Chen et al. (2007) studied the influence of SCR on the emission characteristics of PAHs and showed that adsorptive characteristics of SCR may facilitate the formation of PAHs and increase Nap, BaA, and BbF concentrations. Li et al. (2015) studied the impact of SCR on fine particle emissions from coal-fired power plants. The results showed that as flue gas passed through SCR, generation of new particles from insoluble inorganic/organic compounds may occur. This results in the increase in $\mathrm{PM}_{2.5}$ emissions and PAHs adherence to the new particles. On the other hand, most solid-phase PAHs are composed of 4-6 ring with high TEFs (the TEFs are 100-20,000 times higher than that of 2-3 ring PAHs); the concentrations and overall toxicity contribution of PAHs with 4-6 ring are much higher than those of 2-3 ring PAHs. Therefore, particle removal should be optimized to reduce the emission of solidphase PAHs, especially for the fine particles containing high concentrations of 4-6 ring PAHs.

Table 2 shows the concentrations of gas-phase and solid-phase PAHs and Fig. 4 shows PAH species with different rings in the flue gas of the steel-making processes. The results show that the solid-phase 5-6 ring PAHs of proportion (76\%) in EAF flue gas is higher than SP (20\%). In terms of TEQ, the baghouse effectively captured particles and removed 4-6 ring PAHs which are of high toxicity. The baghouse removed the coarser particles efficiently, and improves the overall removal efficiency, However, the pulse back blowing of baghouse would result in the finer particles being emitted after the baghouse and lead to a high proportion of 5-6 ring PAHs increase. The low removal efficiency (38\%) of the TEQ of solid-phase PAHs in the SP is primarily attributed to the low removal efficiency of fine particles achieved with the APCDs (i.e., DESP + FGD + SCR). Although DESP can capture the particles from SP, capture of fine particles is relatively inefficient. The FGD is a semi-dry scrubber in which alkaline slurry is sprayed during operation and generates multiple particles. The decrease of the flue gas temperature and formation of alkaline particles in the FGD process also contribute to the condensation of gas-phase PAHs. No additional particle removal device such as WESP or baghouses is installed after FGD; therefore, alkaline and fine particles containing 4-6 ring PAH are not effectively captured and lead to the formation of some highly toxic 4-6 ring PAHs.

The removal efficiency of the gas-phase TEQ achieved with the APCDs (DESP + FGD + SCR) of SP and the baghouse of EAF are $80 \%$ and $65 \%$, respectively. Because the FGD adopted by the SP is a low-temperature process and alkaline droplets are sprayed, thereby increasing the removal efficiency of gas-phase PAHs. Within the low-temperature FGD, condensation of gas-phase PAHs is promoted. Overall, removal efficiencies of PAHs based on the mass concentration and TEQ depend on the APCD combination, indicating that the two steel-making processes investigated still have the room for improvement regarding the removal of PAHs. 


\subsubsection{Diagnostic ratios of PAHs}

PAHs are mostly emitted as mixtures and the relative molecular concentration ratio is regarded as a characteristic of specific emission source. PAHs vary significantly in their compositions and concentrations for different high-temperature sources. Because the existing differences between the sampling technique selected and analytical procedures adopted, a great inconsistency exists among the data reported for PAHs source. Thus, exploring the impact of specific emission sources is essential for risk assessment and diagnostic ratio of PAHs may serve as an important tool for identifying the possible sources of pollution. Most diagnostic ratios involve the pairs of PAHs with the same molar mass and similar physicochemical properties. As a basis, the distributions of PAHs congeners in the EAF are analyzed for the diagnostic ratios (Yang et al., 2002; Mackay et al., 2006; Ravindra et al., 2008; Tobiszewski and Namieśnik., 2012).

Fig. 7 shows the congener ratios of PAHs emitted from EAF. The results show that the diagnostic ratios of $\mathrm{FL} / \mathrm{CHR}, \mathrm{FL} /(\mathrm{BaA}+\mathrm{CHR}), \mathrm{Pyr} / 5-\mathrm{MC}$ and $\mathrm{Pyr} /(\mathrm{BaA}+\mathrm{CHR})$ are significantly different from other stationary sources. In this study, the diagnostic ratios of FL/CHR, FL/(BaA + CHR), Pyr/5-MC and $\mathrm{Pyr} /(\mathrm{BaA}+\mathrm{CHR})$ of EAF are 16.6, 12.1, 12.8 and 9.4, respectively. Yang et al. (2002) studied $21 \mathrm{PAHs}$ emitted from EAF, and the results show that the ratios of FL/CHR, FL/(BaA + CHR), Pyr/5$\mathrm{MC}$ and $\mathrm{Pyr} /(\mathrm{BaA}+\mathrm{CHR})$ are 25.3, 10.4, 19.7 and 8.09, respectively. The diagnostic ratios obtained in this study are close and can serve as the diagnostic ratios of PAHs emitted from EAF. On the other hand, this study collected coal-fired boiler diagnostic ratios for comparison. The results show that the average diagnostic ratios of FL/CHR, FL/(BaA + CHR), Pyr/5-MC and Pyr/(BaA + CHR) are $1.03,2.06,1.12$ and 0.73 , respectively, with the average standard deviation of 0.36 (Lu et al., 2019; Lu et al., 2020). The overall results indicate that the diagnostic ratios listed can be applied to help identify the different stationary sources of PAHs emissions.
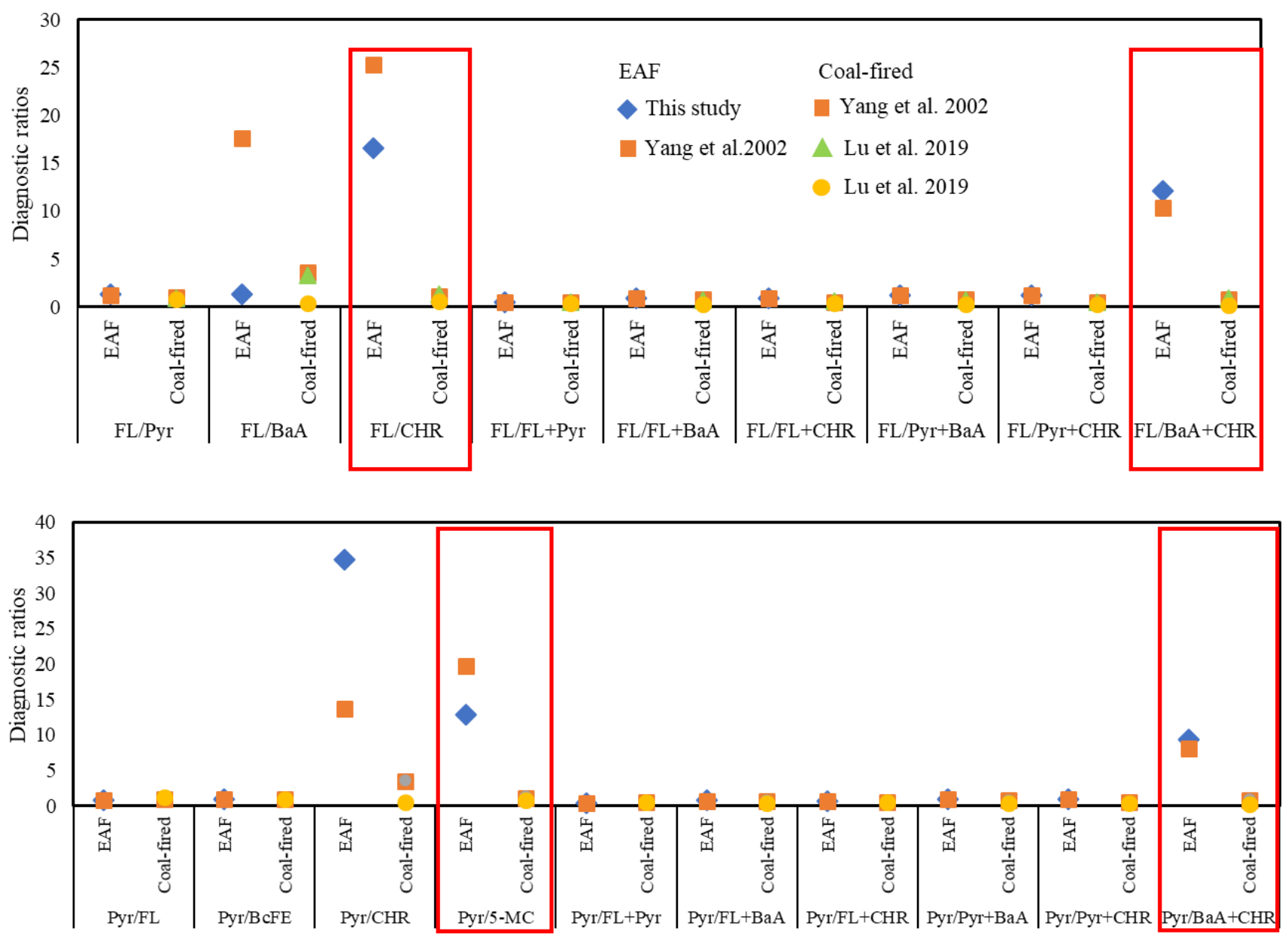

Fig. 7. Congener ratios of PAHs congeners from EAF and different studies coal-fired boiler emission sources. 
In addition, this study uses T-TEST to calculate the $p$-value to determine whether the source is different. If the $p$-value is less than 0.05 , it means that the averages of the two populations are significantly distinct. The diagnostic ratios of FL/CHR in EAF and coal-fired boiler generate a relatively low $p$-value $(p<0.001)$. Furthermore, the $p$-values of $\mathrm{FL} / \mathrm{CHR}, \mathrm{FL} /(\mathrm{BaA}+\mathrm{CHR}), \mathrm{Pyr} / 5$ $\mathrm{MC}$ and $\mathrm{Pyr} /(\mathrm{BaA}+\mathrm{CHR})$ in EAF and coal-fired boilers are 0.0044, 0.0003, 0.0050 and 0.0003, respectively, which are far less than 0.05 . The results indicate that possible source of combustion such as mobile source, coal and oil-burning, and steel-making processes can be identified by specific diagnosis ratios.

\subsection{Emission Factors of Air Pollutants in Two Steel-making Processes}

This study also calculates the pollutant emission factors based on the results obtained and the operating parameters. Additionally, emission factors of pollutants from steel-making process in various countries are collected and compared (Table 3). Regarding the SP, the emission factors of FPM, $\mathrm{FPM}_{2.5}$, and CPM are 13.3, 2.95, and $61.2 \mathrm{~g} \mathrm{ton}^{-1}$, respectively, which are lower than those

Table 3. Emission factors ( $\mathrm{g} \mathrm{ton}^{-1}$ ) of pollutants reported for SP and EAF.

\begin{tabular}{|c|c|c|c|c|c|c|c|}
\hline Studies & APCDs & PM & $\mathrm{PM}_{2.5}$ & $\mathrm{NO}_{\mathrm{x}}$ & $\mathrm{SO}_{\mathrm{x}}$ & PAHs & $\mathrm{CO}$ \\
\hline This study (SP) & $\begin{array}{l}\text { DESP + FGD + } \\
\quad \text { SCR }\end{array}$ & 13.3 & $\begin{array}{l}2.95\left(\mathrm{FPM}_{2.5}\right) \\
61.2\left(\mathrm{CPM}_{2.5}\right)\end{array}$ & 93.5 & 78.8 & 0.102 (27 PAHs) & 10565 \\
\hline Taiwan EPA (2020) & $\mathrm{ESP}+\mathrm{FGD}+\mathrm{SCR}$ & 6.28 & & 181.7 & 107.7 & & 337.1 \\
\hline \multirow[t]{5}{*}{ U.S. EPA (2009) } & DESP & 800 & & & & & \\
\hline & WESP & 85 & & & & & \\
\hline & $\mathrm{VSCB}^{*}$ & $235-259$ & & & & & \\
\hline & CYC & 500 & & & & & \\
\hline & $\mathrm{BH}$ & $4.5-150$ & & & & & \\
\hline EU (2010) & $\mathrm{ESP}$ or $\mathrm{BH}$ & $40.7-559.4$ & & 302.1-1031.2 & 219.9-973.3 & $\begin{array}{c}0.0002-0.9517 \\
\text { (16 PAHs) }\end{array}$ & $\begin{array}{l}8783- \\
37000\end{array}$ \\
\hline Yang et al. (2002) & $\mathrm{BH}$ & & & & & 0.072 (21 PAHs) & \\
\hline Wang et al. (2016) & ESP & & 500 & 600 & 3200 & & 22000 \\
\hline Wu et al. (2015) & WFGD & & $211-540$ & $522-612$ & $2400-2800$ & & \\
\hline Lo et al. (2017) & $\mathrm{ESP}+\mathrm{SCR}+\mathrm{FGD}$ & $2.7-10.8$ & & $1.2-181.7$ & $0.8-107.7$ & & $0.03-337.1$ \\
\hline Studies & APCDs & PM & $\mathrm{PM}_{2.5}$ & $\mathrm{NO}_{\mathrm{x}}$ & $\mathrm{SO}_{\mathrm{x}}$ & PAHs & $\mathrm{CO}$ \\
\hline This study (EAF) & $\mathrm{CO}$ con. $^{* *}+\mathrm{BH}$ & 170.6 & $\begin{array}{l}40.2\left(\mathrm{FPM}_{2.5}\right) \\
43.0\left(\mathrm{CPM}_{2.5}\right)\end{array}$ & 16.8 & 35.9 & 1.701 (27 PAHs) & 2996 \\
\hline Taiwan EPA (2020) & $\begin{array}{l}\mathrm{CO}-\text { con. }^{* *}+\mathrm{CYC} \\
+\mathrm{BH}\end{array}$ & 23.88 & & 96.1 & 79.8 & & 129.5 \\
\hline Taiwan THS (2019) & 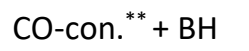 & $3.62-101.76$ & & $7.4-217$ & $23-285$ & & 335.4 \\
\hline Taiwan JSS (2019) & CO-con. ${ }^{* *}+\mathrm{BH}$ & $9.52-483.35$ & & $60-326$ & $35-496$ & & $1247-1521$ \\
\hline U.S. EPA (2009) & uncontrolled & 19000 & & & & & \\
\hline & $\mathrm{BH}$ & 21.5-150 & $\begin{array}{c}9.07\left(\mathrm{FPM}_{2.5}\right) \\
4.54-13.15 \\
\left(\mathrm{CPM}_{2.5}\right)\end{array}$ & 99.79 & & & 816.5 \\
\hline & $\mathrm{BH}$ & & $4.54\left(\mathrm{CPM}_{2.5}\right)$ & & & & \\
\hline Taiwan EPA (2014) & & & & 100 & 35 & & \\
\hline China MEE. (2017) & $\mathrm{BH}$ & $86-105$ & & & & & \\
\hline Lai (1998) & $\begin{array}{l}\mathrm{CYC} \\
\mathrm{BH}\end{array}$ & & & & & 456-1190 & \\
\hline Yang et al. (2002) & $\mathrm{BH}$ & & & & & $\begin{array}{l}\text { 1.48-18.5 } \\
\text { (21 PAHs) }\end{array}$ & \\
\hline EU (2010) & - & & & & & & $50-4500$ \\
\hline Wang et al. (2016) & $\mathrm{BH}$ & & $\begin{array}{c}1.13-1900 \\
\left(\mathrm{PM}_{2.5}\right) \\
2070\left(\mathrm{PM}_{10}\right)\end{array}$ & & & & \\
\hline
\end{tabular}

\footnotetext{
${ }^{*}$ Venturi scrubber. ${ }^{* *} \mathrm{CO}$ converter.
} 
reported in the US, EU, and China. The emission factors of $\mathrm{NO}_{x}\left(93.5 \mathrm{~g} \mathrm{ton}^{-1}\right)$, and $\mathrm{SO}_{x}\left(78.8 \mathrm{~g} \mathrm{ton}^{-1}\right)$ in the SP of this study are lower than those of China and EU. The results indicate that the raw material and operating conditions of the APCDs in this SP are well controlled.

As for EAF, the results show that the emission factors of FPM, FPM 2.5 , and CPM are 170.6, 40.2, and $43.0 \mathrm{~g} \mathrm{ton}^{-1}$, respectively. Overall, the emission factors of these pollutants are lower than those of the EAF in China but slightly higher than those reported in the United States (US) and European Union (EU). Therefore, the pollution control of the EAF should be further improved. Moreover, the emission factors of $\mathrm{NO}_{x}\left(16.8 \mathrm{~g} \mathrm{ton}^{-1}\right)$ from the EAF is lower than those reported for most domestic and foreign EAFs, while that of $\mathrm{SO}_{\mathrm{x}}\left(35.9 \mathrm{~g} \mathrm{ton}^{-1}\right)$ which is slightly higher than that the reported in some EU countries and China.

Additionally, the emission factors of PAHs in the SP and EAF of this study are calculated as 0.102 and $1.701 \mathrm{~g} \mathrm{ton}^{-1}$, respectively, which are significantly higher than those reported for a coal-fired power plant by Yin et al. (2013) in China (0.0182 $\mathrm{g} \mathrm{ton}^{-1}$ of coal for $16 \mathrm{PAHs}$ ) and Hsu et al. (2016) in Taiwan (0.00156 $\mathrm{g}_{\text {ton }}{ }^{-1}$ of coal for $16 \mathrm{PAHs}$ ). Moreover, the emission factor of PAHs emitted from EAF is significantly higher than that of SP, and the difference in PAHs emission concentration is nearly 2 times. EAF is only equipped with a baghouse, so that gas-phase PAHs cannot be effectively trapped. In addition, $\operatorname{EAF}\left(2,263,794 \mathrm{Nm}^{3} \mathrm{hr}^{-1}\right)$ exhaust gas emissions are 2.8 times that of SP $\left(805,626 \mathrm{Nm}^{3} \mathrm{hr}^{-1}\right)$. On the other hand, regarding the emission factors of SP, it is significantly lower than that of EU and close to the 21 PAHs emission factors studied by Yang et al. (2002). Furthermore, the emission factors of PAHs in the EAF investigated is lower than that reported by Yang et al. (2002) and Lai (1998).

$\mathrm{CO}$ is used as an indicator of combustion efficiency and pollution emissions. Regarding the SP and EAF investigated, the emission factors of $\mathrm{CO}$ are 10,565 and 2,996 $\mathrm{g} \mathrm{ton}^{-1}$, respectively. the emission factor of CO from SP is significantly higher than that of EAF. Compared with EU statistics, this factor is within the EU range of 8,783-37,000 $\mathrm{g} \mathrm{ton}^{-1}$, which is lower than that reported by Wang et al. (2016). However, the CO emission factor of this study are much higher than those reported by Lo et al. (2017) and Taiwan EPA (2020). The CO emission factor from EAF of this study is significantly higher than most reports but lower than the EU. There are many possible reasons for the difference in emission factor reported, such as: 1. the boiler type, feed material, properties and compositions (e.g., type, size, shape, moisture content, and bulk density), 2. flue gas flow rate affects emissions (SP and EAF are 805,626 and 2,263,794 $\mathrm{Nm}^{3} \mathrm{hr}^{-1}$, respectively.), 3. operating temperature and oxygen supply, and 4. combustion method, removal performance, and operating conditions (e.g., fuel/air mixing ratio) (Wu et al., 2018; Wu et al., 2021)

\section{CONCLUSIONS}

In this study, representative SP and EAF are selected for simultaneous samplings and measurements of various pollutants (FPM, $\mathrm{FPM}_{2.5}, \mathrm{CPM}, \mathrm{SO}_{\mathrm{x}}, \mathrm{NO}_{\mathrm{x}}, \mathrm{PAHs}$ and $\mathrm{CO}$ ) at the APCD inlet and stack, respectively. Additionally, the removal efficiencies of pollutants achieved with existing APCDs and the emission characteristics/intensities of the two steel-making processes are investigated. The results can be summarized as follows:

1. The concentrations of $\mathrm{NO}_{x}, \mathrm{SO}_{x}, \mathrm{HCl}$, and $\mathrm{NH}_{3}$ emitted from the SP are $43,17,<0.1$, and $2.4 \mathrm{ppm}$, respectively; while the concentrations of all four gaseous pollutants emitted from the EAF are $<1 \mathrm{ppm}$. The $\mathrm{NH}_{3}$ concentration emitted from the SP is $2.4 \mathrm{ppm}$, and the operating conditions of SCR should be optimized to reduce $\mathrm{NO}_{x}$ and $\mathrm{NH}_{3}$ emissions and to suppress CPM formation.

2. The FPM concentrations measured at the stacks of the SP and EAF are $8.2 \pm 1.3$ and $13.6 \pm$ $2.2 \mathrm{mg} \mathrm{Nm}^{-3}$, respectively, while $F_{2} \mathrm{MM}_{2.5}$ emitted are $1.8 \pm 0.5$ and $3.2 \pm 1.1 \mathrm{mg} \mathrm{Nm}^{-3}$, respectively.

3. The concentration of CPM emitted from the SP and EAF are $37.7 \pm 1.3$ and $3.4 \pm 0.8 \mathrm{mg} \mathrm{Nm}^{-3}$, respectively. The concentration of CPM emitted from the SP is relatively high and merits further investigation for reduction.

4. The total concentration of $27 \mathrm{PAHs}$ species emitted from SP is reduced to $62.6 \mu \mathrm{g} \mathrm{Nm}^{-3}$ with the use of APCDs (DESP + FGD + SCR), and the overall removal efficiency of PAHs achieved with the APCDs reaches $72 \%$. On the other hand, the removal efficiency of 27 PAHs species 
achieved with the baghouse of EAF is not significant (26\%), indicating that baghouse did not efficiently reduce PAHs emissions.

5. As the flue gas passed through the APCDs, the gas- and solid-phase PAHs in the exhaust of SP are primarily 2-3 ring remained as the dominant species. HMW PAHs are effectively removed by APCD, but LMW PAHs are difficult to remove with existing APCD; As the EAF flue gas passes through the baghouse, the 4-5 ring gas- and solid-phase PAHs are effectively captured and removed, but solid-phase 6-ring PAHs is significantly increased trend.

6. The PAH TEQ concentrations measured at the stacks of SP and EAF are 5.45 and $4.74 \mu \mathrm{g} \mathrm{Nm}^{-3}$, respectively, which are much higher than those reported for coal-burning processes. The formation characteristics and control strategy for PAHs emitted from the steel-making industry require further study.

7. The diagnosis ratios of $\mathrm{FL} / \mathrm{CHR}, \mathrm{FL} /(\mathrm{BaA}+\mathrm{CHR}), \mathrm{Pyr} / 5-\mathrm{MC}$ and $\mathrm{Pyr} /(\mathrm{BaA}+\mathrm{CHR})$ are suggested as indicators for EAF.

8. The emission factors of FPM,$F^{2} M_{2.5}$ and CPM in the SP in this study are lower than those reported in China, EU and US, but the emission factors of FPM, FPM 2.5 , and CPM in the EAF are slightly higher than those reported in the US and EU. However, emission factors of PAHs from SP and EAF are significantly higher than coal-fired power plant. Therefore, it is necessary to continue to pay attention to PAHs emissions from steel plants.

9. The emission factors of CO in SP and EAF are 10,565 and 2,996 $\mathrm{g} \mathrm{ton}^{-1}$, respectively. The CO emission factors are significantly higher than most studies and more effort are needed to reduce the emission from these two steel-making processes.

\section{ACKNOWLEDGMENTS}

The authors gratefully acknowledge the financial supports provided by the Ministry of Science and Technology and Environmental Protection Administration, Executive Yuan of Taiwan (MOST107-EPA-F-006-004.DOC; MOST-109-2622-8-009-017-TE5).

\section{DISCLAIMER}

\section{Ethics Approval and Consent to Participate \\ Not applicable}

\section{Consent for Publication}

Not applicable

\section{Availability of Data and Materials}

All data generated or analyzed during this study are included in this published article [and its supplementary information files].

\section{Competing Interests \\ Not applicable}

\section{Authors Contributions}

Tang-Wei Chen developed and designed the methodology of this experiment and prepared the original draft. Jyh Cherng Chen and Zhen Shu Liu reviewed and edit the published work by those from the original research group, and management and coordination responsibility for the research activity planning and execution. Tang-Wei Chen and Kai-Hsien Chi conducted a research and investigation process, specifically performing the experiments, or data/evidence collection. Moo Been Chang supervised the project and had the oversight and leadership responsibility for the research activity planning and execution, including mentorship external to the core team. All authors read and approved the final manuscript. 


\section{SUPPLEMENTARY MATERIAL}

Supplementary material for this article can be found in the online version at https://doi. org/10.4209/aaqr.210140

\section{REFERENCES}

Amodio, M., Andriani, E., De Gennaro, G., Di Gilio, A., lelpo, P., Placentino, C., Tutino, M. (2013). How a steel plant affects air quality of a nearby urban area: A study on metals and PAH concentrations. Aerosol Air Qual. Res. 13, 497-508. https://doi.org/10.4209/aaqr.2012.09.0254

Andersson, J.T., Achten, C. (2015). Time to say goodbye to the 16 EPA PAHs? Toward an up-to-date use of PACs for environmental purposes. Polycyclic Aromat. Compd. 35, 330-354. https://doi.org/10.1080/10406638.2014.991042

Blumenstock, M., Zimmermann, R., Schramm, K.W., Kettrup, A. (2000). Influence of combustion conditions on the PCDD/F-, PCB-, PCBz-and PAH-concentrations in the post-combustion chamber of a waste incineration pilot plant. Chemosphere 40, 987-993. https://doi.org/10.10 16/s0045-6535(99)00343-4

Busca, G., Lietti, L., Ramis, G., Berti, F. (1998). Chemical and mechanistic aspects of the selective catalytic reduction of $\mathrm{NO}_{x}$ by ammonia over oxide catalysts: A review. Appl. Catal., B 18, 1-36. https://doi.org/10.1016/S0926-3373(98)00040-X

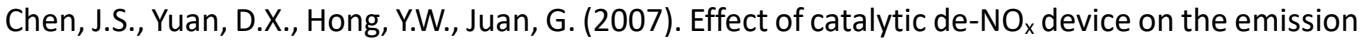
characteristics of polycyclic aromatic hydrocarbon in flue gas. J. Fuel Chem. Technol. 35, 722726. https://doi.org/10.1016/S1872-5813(08)60006-7

Chen, Y.C., Tsai, P.J., Mou, J.L., Kuo, Y.C., Wang, S.M., Young, L.H., Wang, Y.F. (2012). A pilot study for determining the optimal operation condition for simultaneously controlling the emissions of PCDD/Fs and PAHs from the iron ore sintering process. Chemosphere 88, 1324-1331. https://doi.org/10.1016/j.chemosphere.2012.05.031

Cheruiyot, N.K., Lee, W.J., Mwangi, J.K., Wang, L.C., Lin, N.H., Lin, Y.C., Cao, J., Zhang, R., ChangChien, G.P. (2015). An overview: Polycyclic aromatic hydrocarbon emissions from the stationary and mobile sources and in the ambient air. Aerosol Air Qual. Res. 15, 2730-2762. https://doi.org/10.4209/aaqr.2015.11.0627

Crolla, D.(2015). Encyclopedia of automotive engineering, John Wiley \& Sons.

European Union (EU) (2010). Best Available Techniques (BAT) Reference Document for Iron and Steel Production, Industrial Emissions Directive 2010/75/EU (Integrated Pollution Prevention and Control).

Gong, B., Kim, J., Kim, H., Lee, S., Kim, H., Jo, J., Kim, J., Gang, D., Park, J.M., Hong, J. (2016). A study on the characteristics of condensable fine particles in flue gas. JKOSAE 32, 501-512. https://doi.org/10.5572/KOSAE.2016.32.5.501

Heck, R.M., Farrauto, R.J., Gulati, S.T. (2016). Catalytic air pollution control: Commercial technology. John Wiley \& Sons. https://doi.org/10.1002/9781118397749

Hsu, W.T., Liu, M.C., Hung, P.C., Chang, S.H., Chang, M.B. (2016). PAH emissions from coal combustion and waste incineration. J. Hazard. Mater. 318, 32-40. https://doi.org/10.1016/j.jha zmat.2016.06.038

Khaparde, V., Bhanarkar, A., Majumdar, D., Rao, C.C. (2016). Characterization of polycyclic aromatic hydrocarbons in fugitive $\mathrm{PM}_{10}$ emissions from an integrated iron and steel plant. Sci. Total Environ. 562, 155-163. https://doi.org/10.1016/j.scitotenv.2016.03.153

Lai, S. (1998). Characteristics of PAHs and metal elements in the stack flue gas of the steel and iron industries. Dissertation. National Cheng Kung University, Taiwan.

Li, J., Li, X., Li, M., Lu, S., Yan, J., Xie, W., Liu, C., Qi, Z. (2016). Influence of air pollution control devices on the polycyclic aromatic hydrocarbon distribution in flue gas from an ultralowemission coal-fired power plant. Energy Fuels 30, 9572-9579. https://doi.org/10.1021/acs.en ergyfuels.6b01381

Li, X., Sun, W., Zhao, L., Cai, J. (2019a). Emission characterization of particulate matter in the ironmaking process. Environ. Technol. 40, 282-292. https://doi.org/10.1080/09593330.2017.1 387180 
Li, X., Zhou, C., Li, J., Lu, S., Yan, J. (2019b). Distribution and emission characteristics of filterable and condensable particulate matter before and after a low-low temperature electrostatic precipitator. Environ. Sci. Pollut. Res. 26, 12798-12806. https://doi.org/10.1007/s11356-01904570-y

Li, Z., Jiang, J., Ma, Z., Wang, S., Duan, L. (2015). Effect of selective catalytic reduction (SCR) on fine particle emission from two coal-fired power plants in China. Atmos. Environ. 120, 227233. https://doi.org/10.1016/j.atmosenv.2015.08.046

Lo, C., Chang, H.C., Lu., Y.T., Chen, Y.L. (2017). The determination and review of air emission standards in steel industry. Sinotech Engineering, 136. 25-33

Lu, C.M., Dat, N.D., Lien, C.K., Chi, K.H., Chang, M.B. (2019). Characteristics of fine particulate matter and polycyclic aromatic hydrocarbons emitted from coal combustion processes. Energy Fuels 33, 10247-10254. https://doi.org/10.1021/acs.energyfuels.9b02201

Lu, S., Wu, Y., Chen, T., Song, J., Xu, Z., Tang, M., Ding, S. (2020). Influence of the combination system of wet flue gas desulfurization and a wet electrostatic precipitator on the distribution of polycyclic aromatic hydrocarbons in flue gas from a coal-fired industrial plant. Energy Fuels 34, 5707-5714. https://doi.org/10.1021/acs.energyfuels.0c00389

Mackay, D., Shiu, W. Y., Lee, S.C. (2006). Handbook of physical-chemical properties and environmental fate for organic chemicals. CRC Press.

Ministry of ecology and environment of People's Republic of China (China MEE) (2017). Technical specifications for discharge permit application and issuance-steel industry. National Environmental Protection Standard HJ846 of People's Republic of China.

Nisbet, I.C., Lagoy, P.K. (1992). Toxic equivalency factors (TEFs) for polycyclic aromatic hydrocarbons (PAHs). Regul. Toxicol. Pharmacol. 16, 290-300. https://doi.org/10.1016/02732300(92)90009-X

Odabasi, M., Bayram, A., Elbir, T., Seyfioglu, R., Dumanoglu, Y., Bozlaker, A., Demircioglu, H., Altiok, H., Yatkin, S., Cetin, B. (2009). Electric arc furnaces for steel-making: hot spots for persistent organic pollutants. Environ. Sci. Technol. 43, 5205-5211. https://doi.org/10.1021/es900863s

Oh, J.E., Gullett, B., Ryan, S., Touati, A. (2007). Mechanistic relationships among PCDDs/Fs, PCNs, PAHs, ClPhs, and ClBzs in municipal waste incineration. Environ. Sci. Technol. 41, 4705-4710. https://doi.org/10.1021/es0629716

Ravindra, K., Sokhi, R., Van Grieken, R. (2008). Atmospheric polycyclic aromatic hydrocarbons: source attribution, emission factors and regulation. Atmos. Environ. 42, 2895-2921. https://doi.org/10.1016/j.atmosenv.2007.12.010

Taiwan Environmental Protection Administration (Taiwan EPA) (2014). Sulfur oxide and nitrogen oxide emission coefficients and control efficiency requirements for the declaration of air pollution prevention and control fees for fixed pollution sources in public and private places. Environmental Protection Administration, Taiwan.

Taiwan Environmental Protection Administration (Taiwan EPA) (2020). Fixed pollution source data disclosure management information platform. Discharge Permit of Steel Plant. Environmental Protection Administration, Taiwan. https://aodmis.epa.gov.tw/opendata/\#/ab/1

Taiwan Jianshun Steel (Taiwan JSS) (2019). Air pollutant sampling and test reports of Jianshun Steel Corporation in Taiwan during 2014-2019. Taiwan Jianshun Steel, Taiwan.

Taiwan Tung Ho Steel (Taiwan THS) (2019). Air pollutant sampling and test reports of Tung Ho Steel Corporation in Taiwan during 2014-2019. Taiwan Tung Ho Steel, Taiwan.

Tang, L., Xue, X., Jia, M., Jing, H., Wang, T., Zhen, R., Huang, M., Tian, J., Guo, J., Li, L., Bo, X., Wang, S. (2020). Iron and steel industry emissions and contribution to the air quality in China. Atmos. Environ. 237, 117668. https://doi.org/10.1016/j.atmosenv.2020.117668

Tobiszewski, M., Namieśnik, J. (2012). PAH diagnostic ratios for the identification of pollution emission sources. Environ. Pollut. 162, 110-119. https://doi.org/10.1016/j.envpol.2011.10.025

United States Environmental Protection Agency (U.S. EPA) (2009). Emission Factor Documentation for AP-42, Section 12.5.1. Environmental Protection Agency, USA.

United States Environmental Protection Agency (U.S. EPA) (2010). Development of a relative potency factor (RPF) approach for polycyclic aromatic hydrocarbon (PAH) mixtures. Intregrated Risk Information Systems (IRIS). Environmental Protection Agency, USA.

Van Thuong, N., Nam, V.D., Hue, N.T.M., Son, L.K., Van Thuy, N., Tung, H.D., Tuan, N.A., Minh, T.B., Minh, N.H. (2014). The emission of polychlorinated dibenzo-p-dioxins and polychlorinated 
dibenzofurans from steel and cement-kiln plants in Vietnam. Aerosol Air Qual. Res. 14, 11891198. https://doi.org/10.4209/aaqr.2013.03.0099

Wang, K., Tian, H., Hua, S., Zhu, C., Gao, J., Xue, Y., Hao, J., Wang, Y., Zhou, J. (2016). A comprehensive emission inventory of multiple air pollutants from iron and steel industry in China: Temporal trends and spatial variation characteristics. Sci. Total Environ. 559, 7-14. https://doi.org/10.1016/j.scitotenv.2016.03.125

Wang, R., Liu, G., Sun, R., Yousaf, B., Wang, J., Liu, R., Zhang, H. (2018). Emission characteristics for gaseous-and size-segregated particulate PAHs in coal combustion flue gas from circulating fluidized bed (CFB) boiler. Environ. Pollut. 238, 581-589. https://doi.org/10.1016/j.envpol.201 8.03.051

Wang, S., Ji, Y., Zhao, J., Lin, Y., Lin, Z. (2020). Source apportionment and toxicity assessment of $\mathrm{PM}_{2.5}$-bound PAHs in a typical iron-steel industry city in northeast China by PMF-ILCR. Sci. Total Environ. 713, 136428. https://doi.org/10.1016/j.scitotenv.2019.136428

World Steel Association (2020). Electronic resource. https://www.worldsteel.org/

Wu, B., Tian, H., Hao, Y., Liu, S., Liu, X., Liu, W., Bai, X., Liang, W., Lin, S., Wu, Y. (2018). Effects of wet flue gas desulfurization and wet electrostatic precipitators on emission characteristics of particulate matter and its ionic compositions from four $300 \mathrm{MW}$ level ultralow coal-fired power plants. Environ. Sci. Technol. 52, 14015-14026. https://doi.org/10.1021/acs.est.8b03656

Wu, X., Zhao, L., Zhang, Y., Zheng, C., Gao, X., Cen, K. (2015). Primary air pollutant emissions and future prediction of iron and steel industry in China. Aerosol Air Qual. Res. 15, 1422-1432. https://doi.org/10.4209/aaqr.2015.01.0029

Wu, X., Liu, W., Gao, H., Alfaro, D., Sun, S., Lei, R., Jia, T., Zheng, M. (2021). Coordinated effects of air pollution control devices on $\mathrm{PAH}$ emissions in coal-fired power plants and industrial boilers. Sci. Total Environ. 756, 144063. https://doi.org/10.1016/j.scitotenv.2020.144063

Xiao, L.S., Wang, R., Chiang, P.C., Pan, S.Y., Guo, Q.H., Chang, E. (2013). Comparative life cycle assessment (LCA) of accelerated carbonation processes using steelmaking slag for $\mathrm{CO}_{2}$ fixation. Aerosol Air Qual. Res. 14, 892-904. https://doi.org/10.4209/aaqr.2013.04.0121

Yang, H.H., Lai, S.O., Hsieh, L.T., Hsueh, H.J., Chi, T.W. (2002). Profiles of PAH emission from steel and iron industries. Chemosphere 48, 1061-1074. https://doi.org/10.1016/S0045-6535(02)00 175-3

Yang, H.H., Lee, K.T., Hsieh, Y.S., Luo, S.W., Li, M.S. (2014). Filterable and condensable fine particulate emissions from stationary sources. Aerosol Air Qual. Res. 14, 2010-2016. https://doi.org/10.4209/aaqr.2014.08.0178

Yang, H.H., Lee, K.T., Hsieh, Y.S., Luo, S.W., Huang, R.J. (2015). Emission characteristics and chemical compositions of both filterable and condensable fine particulate from steel plants. Aerosol Air Qual. Res. 15, 1672-1680. https://doi.org/10.4209/aaqr.2015.06.0398

Yin, X.F., Yang, W.T., Xue, H.M. (2013). PAHs emission characteristics and assessment from the coal combustion process in the large capacity power plant boilers. Adv. Mater. Res. 726-731, 19081916. https://doi.org/10.4028/www.scientific.net/AMR.726-731.1908

Yu, J., Lim, S., Song, J., Lee, D., Yu, M., Kim, J. (2018). A study on the change of condensable particulate matter by the $\mathrm{SO}_{2}$ concentration among combustion gases. JKOSAE 34, 651-658. https://doi.org/10.5572/kosae.2018.34.5.651

Zhang, L., Yang, L., Zhou, Q., Zhang, X., Xing, W., Wei, Y., Hu, M., Zhao, L., Toriba, A., Hayakawa, K. (2020). Size distribution of particulate polycyclic aromatic hydrocarbons in fresh combustion smoke and ambient air: A review. J Environ Sci 88, 370-384. https://doi.org/10.1016/j.jes.201 9.09.007

Zhao, Z., Du, Q., Zhao, G., Gao, J., Dong, H., Cao, Y., Han, Q., Yuan, P., Su, L. (2014). Fine particle emission from an industrial coal-fired circulating fluidized-bed boiler equipped with a fabric filter in China. Energy Fuels 28, 4769-4780. https://doi.org/10.1021/ef500558g 